Research Article

\title{
Mechanical and Acoustic Emission Responses of Rock Fragmentation under Disc Cutter Penetration
}

\author{
Qi Liu $\left(\mathbb{D},{ }^{1}\right.$ Yucong Pan $\mathbb{D}^{2},{ }^{2}$ and Penghai Deng $\mathbb{D}^{2}$ \\ ${ }^{1}$ Changjiang Institute of Survey, Planning, Design and Research, Wuhan 430010, China \\ ${ }^{2}$ School of Civil Engineering, Wuhan University, Wuhan 430072, China \\ Correspondence should be addressed to Qi Liu; liuq9109@163.com
}

Received 25 May 2020; Revised 3 January 2021; Accepted 8 February 2021; Published 23 February 2021

Academic Editor: Timo Saksala

Copyright (c) 2021 Qi Liu et al. This is an open access article distributed under the Creative Commons Attribution License, which permits unrestricted use, distribution, and reproduction in any medium, provided the original work is properly cited.

To better understand the rock fragmentation mechanism and optimize cutter design and selection for rock excavation by TBM, a set of three-dimensional indentation tests was conducted with different rock and cutter types. Acoustic emission (AE) monitoring technique was employed to capture the information of the rock damage evolution real-timely. It is found that the penetration by using the constant cross section (CCS) cutter tends to induce inconspicuous rock chips formation before the sudden occurrence of the macrocrack, but that by using the V-type cutter tends to induce gradual rock fragmentation accompanied by the multiple local rock chips formation and the sawtooth force-penetration curve. Meanwhile, rock fragmentation models for CCS and V-type cutters were compared, and the spatio-temporal evolution of $\mathrm{AE}$ events was quantitatively analyzed to reflect the rock damage zone development process. Results indicate that the V-type cutter has greater penetration ability and the CCS cutter can cause larger unit damage zone radius. Microscopic observation by using the scanning electron microscope (SEM) reveals that the fracture mechanism for the crushed zone of rock is mainly shear type and that for the major crack is tensile type. It does not matter with rock types or cutter types.

\section{Introduction}

Tunnel boring machine (TBM) is an engineering machine for tunnel excavation that is highly automated and widely used. Its application areas contain traffic tunnel, water conveyance tunnel, coal mine roadway, and other underground openings. TBM operation mainly depends on the cutting action of the tools mounted on the cutterhead, including disc or roller cutters for rock excavation and scrapers or chisels for soil excavation. For rock excavation by using the disc cutter, the proper understanding of rock fragmentation mechanism is the foundation of efficient cutters selection, design, arrangement, and TBM operation optimization [1-4].

Rock fragmentation mechanism and tool cutting efficiency under different cutting conditions have been widely studied using various approaches, including theoretical analysis $[5,6]$, laboratory test $[1,2,7,8]$, numerical simulation [9-12], empirical formula [13, 14], and field study $[15,16]$. In the laboratory, the full-scale rock cutting test proves a proper research method to conduct TBM cutterhead design and performance prediction $[9,17,18]$. However, the invisibility of inner damaging and cracking behavior in rock and its large specimen size (e.g., the dimension $1.0 \times 1.0 \times 0.6 \mathrm{~m}$ used by Gong et al. [19]) make it difficult to effectively and detailedly capture the rock fragmentation information. The indentation test using scaled rock specimens simplifies the complicated, dynamic, and violent rock cutting process as the elementary, quasistatic, and localized cutter penetration process. With some synchronous and nondestructive measurement techniques, the real-time rock damaging evolution and cracking development inside the scaled rock specimen can be recorded, and it makes deep research of rock fragmentation mechanism achievable.

Two-dimensional indentation tests using plate rock specimens are usually conducted to investigate the rock fragmentation mechanism because the rock damaging and cracking behaviors can be directly observed from their outer surfaces. Typical cases include observation with electronic speckle pattern interferometry (ESPI) technique conducted by Chen and Labuz [1], observation with the digital image 
correlation (DIC) method conducted by Zhang et al. [20] and Song et al. [21], and observation with infrared thermography (IRT) technique conducted by Liu et al. [22]. However, the confining mode of rock specimen in a twodimensional indentation test cannot simulate the real stress state of rock near the tunnel face during TBM excavation.

With the involvement of biaxial confining stress, threedimensional indentation tests using block rock specimens can overcome the above shortcomings. For example, Liu et al. $[23,24]$ investigated the influence of confining stress on indentation efficiency, crack propagation, chips formation, and optimal spacing of cutters through the indentation test with the groove morphology measurement. However, the test can only reflect the final fragmentation states of rock specimens, rather than the real-time damage evolution processes. Yin et al. [16] explored the influence of confining stress on the crack initiation, distribution and rock fragmentation through indentation tests using granite and marble specimens, and the acoustic emission (AE) system was applied for real-time monitoring, but the damage evolution and cracking process of rock were not fully analyzed due to the limitation of the location accuracy and analysis method. Liu et al. [25] studied the mechanical responses and failure characteristics of soft rock with the multiindentation test, and the load-penetration depth curve was selected as the main analysis object.

On the other hand, the cutter geometry parameters and rock mechanical properties have a significant influence on the fragmentation stress field in rock under indentation [26]. Nevertheless, the existing experimental research studies based on indentation tests may ignore the mechanical behavior and applicability differences of different cutter types, such as the CCS and the V-type cutters. Their front views are shown in Figure 1 [27]. The former is commonly used disc cutter type in rock engineering, and the latter can be chosen for nonabrasive rock excavation to increase cutter penetration or be chosen for very hard rock excavation to reduce the required thrust of effective cutter penetration [17, 28, 29].

The present study aims to experimentally explore the differences of rock fragmentation response induced by different cutter types. During the cutter penetration, the damage development in rock was monitored real-timely using the AE technique with an improved location algorithm. Then, statistical analysis based on the spatial distribution of $\mathrm{AE}$ events was conducted to quantitatively obtain the development law of rock damage zone. Meanwhile, SEM observations were also conducted to intuitively reveal the microcracking mechanisms of different rock fragmentation zones. This study may contribute to a better understanding of rock fragmentation mechanism by using the disc cutter and the further improvement for cutter design, selection, and TBM operation under complex geological conditions.

\section{Cutter Movement and Rock Fragmentation Mechanism}

The basic structure of the TBM disc cutter and its interaction with rock on the tunnel face are shown in Figure 2. During rock cutting, the motion of a disc cutter can be decomposed into two parts, i.e., the revolving movement around the center of cutterhead and that around its shaft axis. Supposing that the motion of the disc cutter is pure rolling without relative sliding to the rock-cutter contact surface and cutter penetration depth is constant, the motion trace of a fixed point on the disc cutter circumference can be expressed using equation (1) and is illustrated in Figure 3 (i.e., O-A-B-C).

$$
\begin{aligned}
& x=r(\theta-\sin \theta), \\
& y=r(1-\cos \theta),
\end{aligned}
$$

where $(x, y)$ denotes the coordinate of the fixed point, $\boldsymbol{r}$ denotes the radius of the disc cutter, and $\boldsymbol{\theta}$ denotes the rotation angle.

In Figure 3, the $\mathrm{B}$ and $\mathrm{C}$ points are, respectively, the start and end of an independent cutting process of the fixed point on the cutter edge, and their transverse motion distance $\Delta x$ can be calculated as follows:

$$
\begin{aligned}
\Delta x & =\left|x_{C}-x_{B}\right|=r \delta-\sqrt{2 r d-d^{2}}, \\
\delta & =\arccos \frac{r-d}{r}
\end{aligned}
$$

where $d$ is the cutter penetration depth and $\delta$ is the rockcutter contact angle. For a disc cutter with $432 \mathrm{~mm}$ (17 in) in diameter and $8 \mathrm{~mm}$ in penetration depth, the calculation of $\triangle x$ is $0.730 \mathrm{~mm}$, and it is far less than the disc cutter size and its penetration depth. That is why the cutter penetration can be regarded as the primary process of rock cutting. Although the revolving movement of the disc cutter actuated by cutterhead torque contributes to the main rock cutting work, it is the penetration movement actuated by cutterhead thrust that plays the dominant role in promoting crack initiation, propagation, and rock chips formation.

Rock fragmentation mechanism under the disc cutter penetration is illustrated in Figure $4[30,31]$. Three typical damage zones in rock can be identified, i.e., the disintegrated and partly recompacted zone, the crushed zone, and the transition or cracked zone. Meanwhile, there mainly exist three types of cracks formed outside the cracked zone, i.e., the major cracks, the radial cracks, and the side cracks, and they dissever the rock into scattered parts. When the side or radial cracks propagate to the rock surface or coalesce with cracks induced by adjacent cutters, some parts of rock can be cut away and rock chips are formed. It is the basic principle for efficient rock fragmentation by using the disc cutter. On the other hand, the development of the crushed zone which is highly fractured and inelastically deformed due to the high compressive stress beneath the disc cutter is also an essential process of rock fragmentation. It is comprised of rock powders or extremely small rock particles and acts as the important force transmission medium for crack initiation and propagation. The crushed zone does not cut rock directly, but its formation can consume about $70-85 \%$ of the cutting energy. During the cutter penetration, the plastic deformation work mainly varies with the volume of the crushed zone. In contrast, the ratio of consumed energy for 


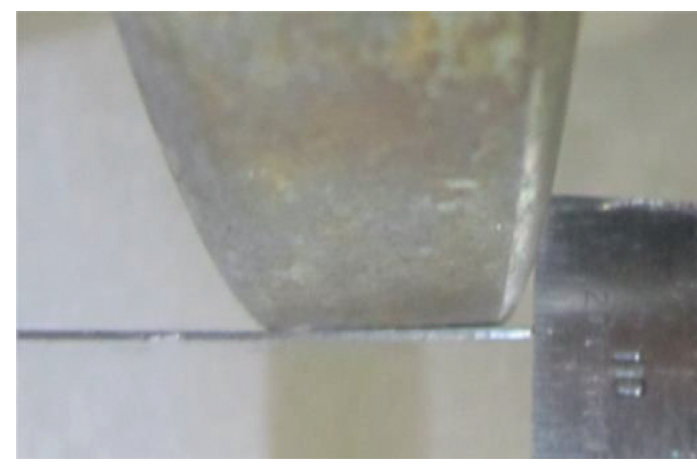

(a)

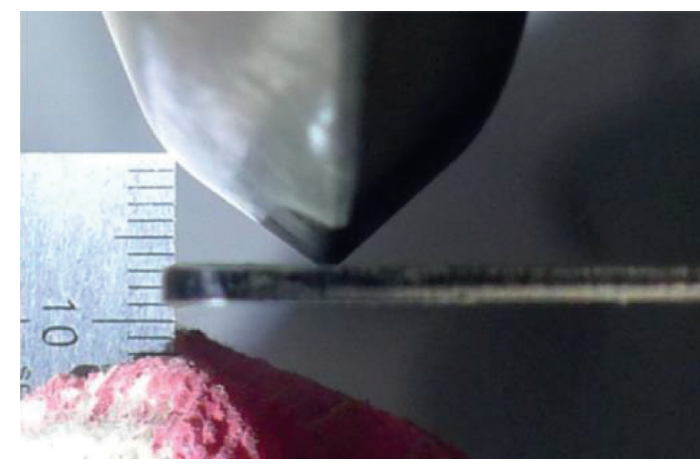

(b)

Figure 1: Front views of disc cutters: (a) CCS cutter; (b) V-type cutter [27].

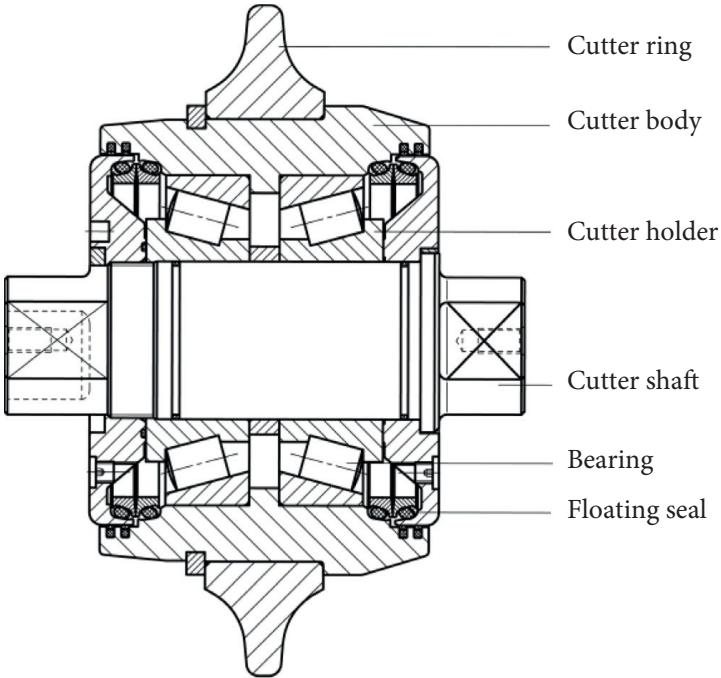

(a)

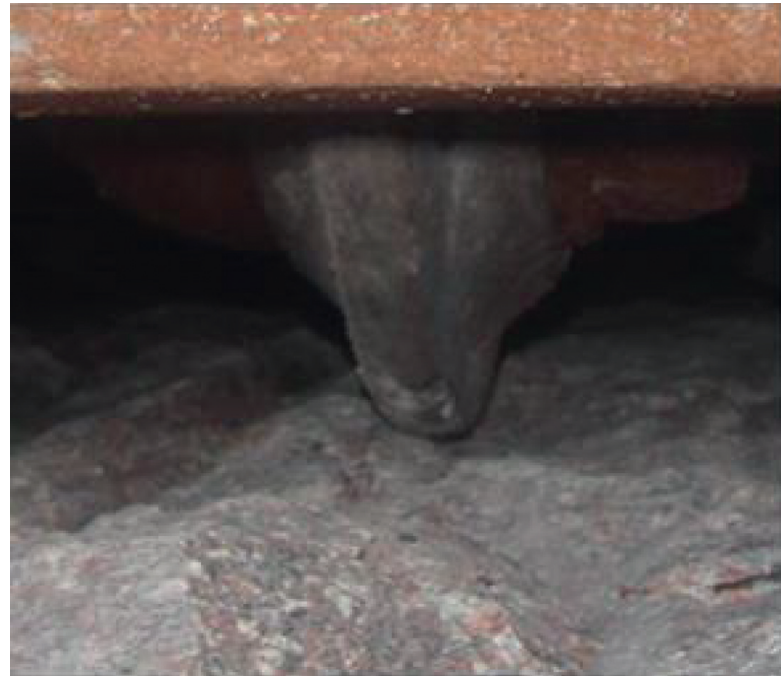

(b)

Figure 2: The basic structure of the TBM disc cutter (a) and its interaction with rock (b).

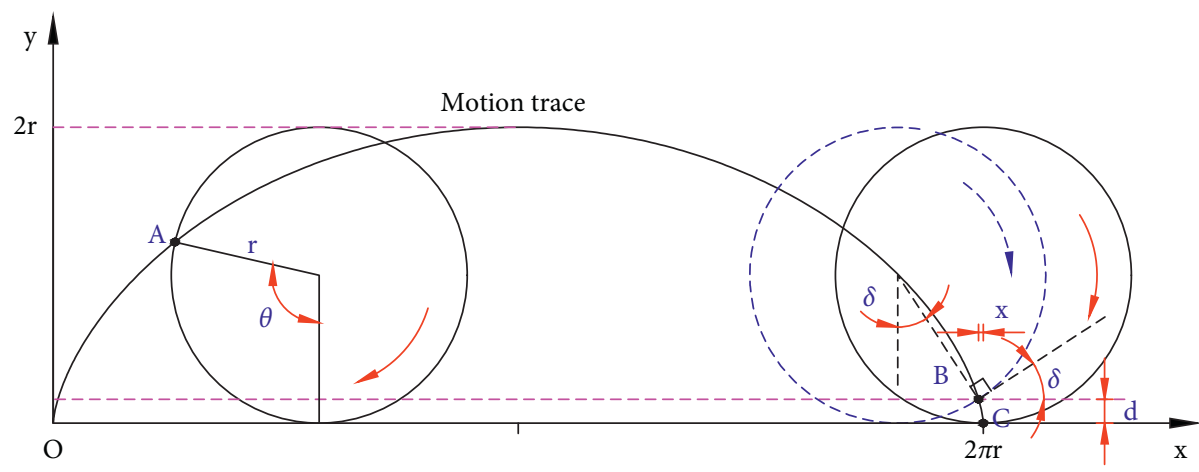

FIgURE 3: Motion trace of a fixed point on the disc cutter circumference.

effective rock chips formation is only $5-10 \%[11,16,32]$. Therefore, when rock chips are formed effectively, the smaller crushed zone means higher cutting efficiency, less rock dust generation, and lower specific energy of cutting $[4,31,33,34]$. The rock damage zone size can be regarded as a significant index to evaluate the cutting efficiency of different disc cutters.

\section{Experiment}

3.1. Rock Specimen Preparation. Two different types of natural rock, including granite (a typical igneous rock) and sandstone (a typical sedimentary rock), respectively, taken from Henan and Chongqing provinces of China, were chosen to investigate their differences in mechanical and $\mathrm{AE}$ 


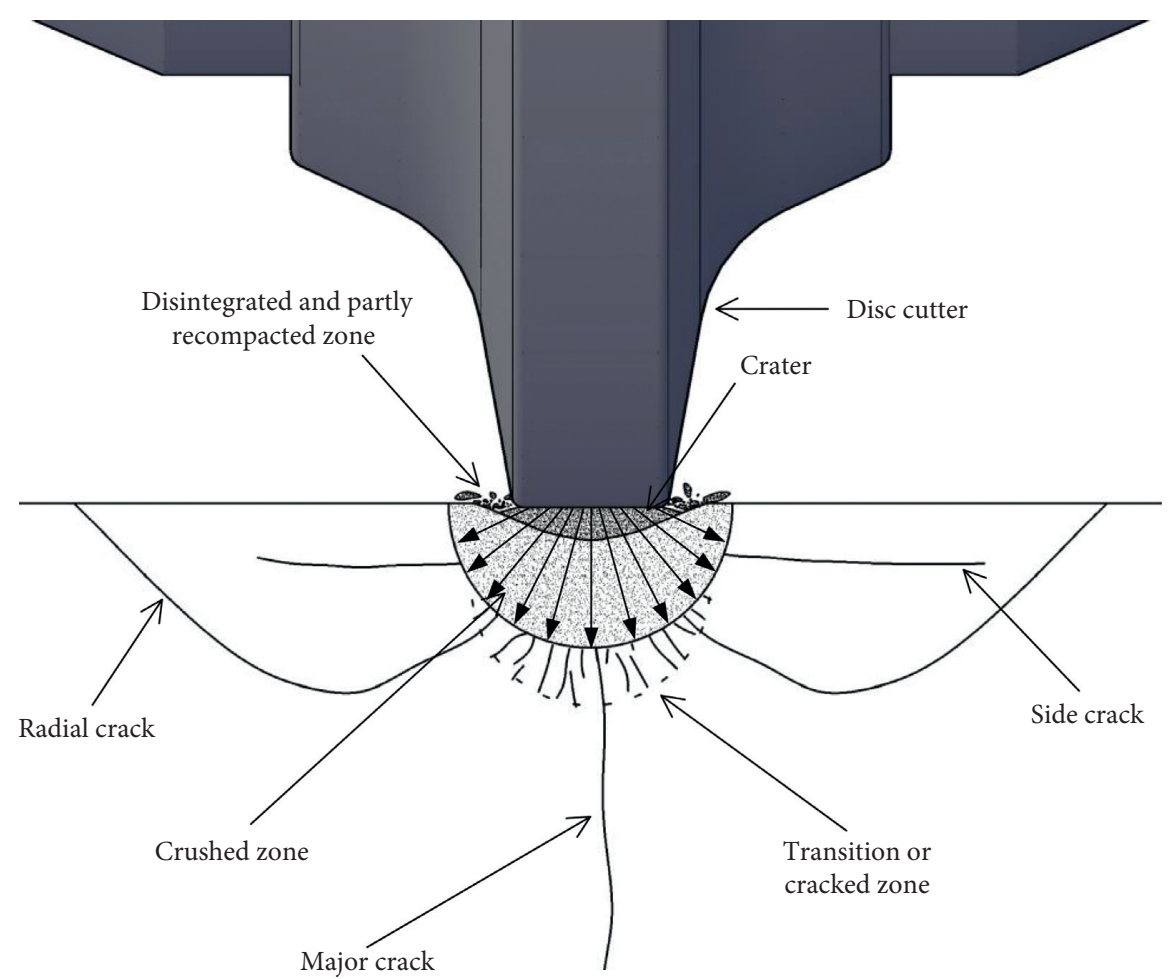

Figure 4: Rock fragmentation mechanism under the disc cutter penetration [30, 31].

responses under the penetration by using CCS and V-type disc cutters. Their main physical and mechanical parameters were obtained through the testing methods suggested by ISRM [35] and are listed in Table 1.

To ensure similar mechanical properties, all rock specimens were incised from the same granite or sandstone block and manufactured in the same dimensions of $150 \times 150 \times 120 \mathrm{~mm}$ (length, width, and height). Grinding and polishing treatments of all surfaces were also conducted to avoid possible stress concentration when exerting the confining stress. Considering the discreteness of test results, two or three same rock specimens were prepared for every test group.

\subsection{Experimental Equipment and Sensor Configuration.} To simulate the real stress state of rock near the tunnel face, a three-dimensional indentation test device was designed and manufactured as shown in Figure 5(a). The thick steel plate and tension rods are combined into a rigid frame and can provide enough lateral mechanical reaction for exerting confining stress. Two horizontal hydraulic jacks act as the lateral loading cells and can exert the biaxial confining stress up to $28 \mathrm{MPa}$ on the abovementioned rock specimen. Four bearing plates which are $30 \mathrm{~mm}$ in thickness were used to ensure uniform loading. The profiles of two scaled disc cutters, i.e., the CCS and V-type cutters, are illustrated in Figures 5(b) and 5(c). To eliminate the size effect, the diameter and edge width of two cutters are, respectively, designed as $120 \mathrm{~mm}$ and $13 \mathrm{~mm}$ [16]. Especially, the scaled V-type cutter has a wedge angle of $120^{\circ}$ and a tip width of $2 \mathrm{~mm}$ to imitate the real V-type cutter $[17,27,36]$. Two cutters are both made of heat-treated alloy steel with high
TABle 1: Physical and mechanical parameters of the granite and sandstone.

\begin{tabular}{lcc}
\hline Parameters & Granite & Sandstone \\
\hline Uniaxial compressive strength $(\mathrm{MPa})$ & 148.45 & 60.46 \\
Elastic modulus $(\mathrm{GPa})$ & 37.22 & 13.55 \\
Poisson's ratio & 0.26 & 0.29 \\
Tensile strength $(\mathrm{MPa})$ & 6.68 & 2.36 \\
Density $\left(\mathrm{g} / \mathrm{cm}^{3}\right)$ & 2.64 & 2.25 \\
\hline
\end{tabular}

hardness (HRC 64) to ensure that they can be approximately regarded as rigid bodies during the cutter indentation. It should be noted that the arc-edged cutter is also an optional TBM disc cutter type for TBM tunnelling engineering. Because the section geometry of the arc-edged cutter is between the CCS cutter and V-type cutter, in order to highlight the differences of rock fragmentation response under the penetration by different cutter types and reduce the test scale, it was not considered as a separate test variable in this study.

To monitor the real-time damage development in rock, the PCI-2 AE testing system produced by Physical Acoustic Corporation (PAC) was employed. As shown in Figure 6, eight Nano30 sensors whose operating frequency ranges from 125 to $750 \mathrm{kHz}$ were attached on the four side surfaces of the rock specimen through premachined holes in bearing plates. The sensors were arranged as the array which follows the staggering layout law, so the monitoring zone can cover the microcracks clustering zone under the disc cutter well. Especially, prefabricated silicone rings which are $3 \mathrm{~mm}$ in thickness and $7.5 \mathrm{~mm}$ in the central hole diameter were 


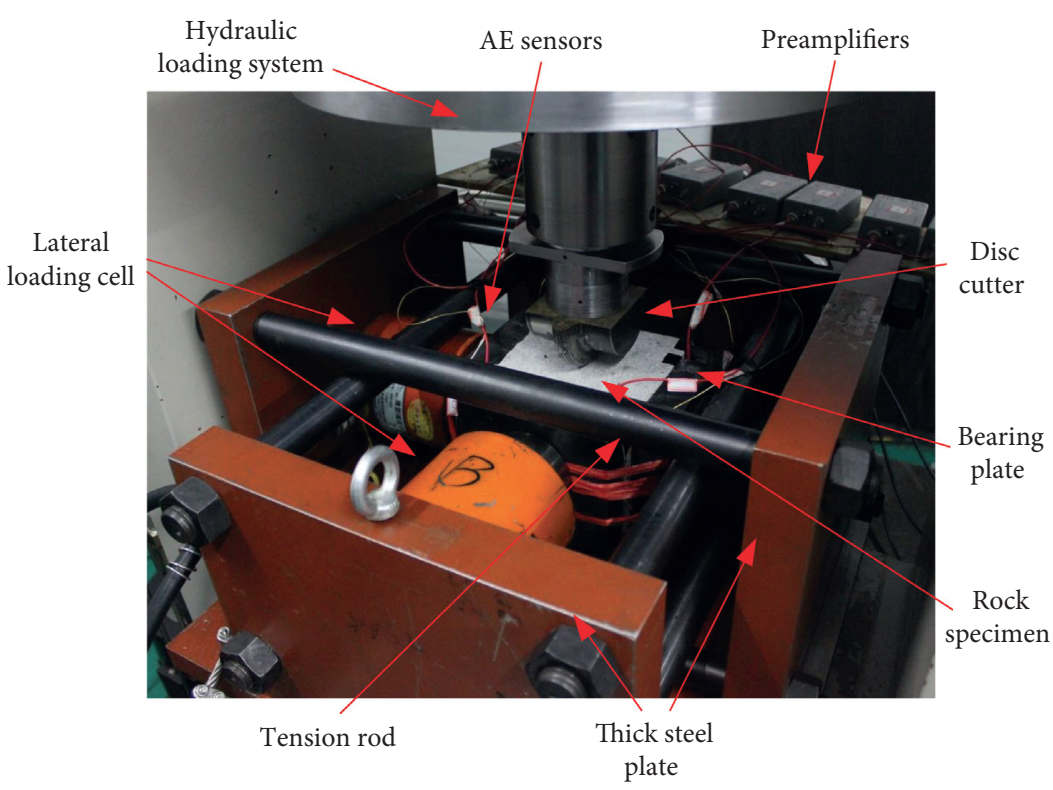

(a)

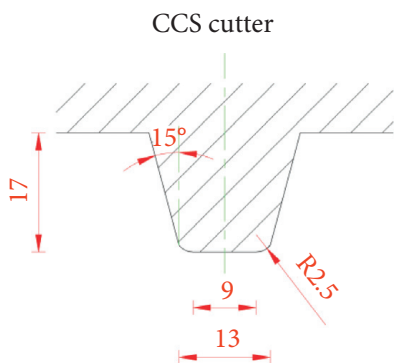

(b)

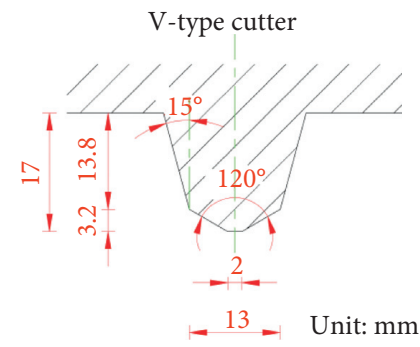

(c)

FIGURE 5: Test system configuration for the indentation test: (a) the test device photo; (b) CCS cutter profile; (c) V-type cutter profile.

utilized to fix sensors through their elastic deformation. These silicone rings were glued firmly on rock surfaces, and after the sensor coated with vacuum grease was embedded into the ring's central hole, the fiberglass tape was used to stick the sensor's back surface. Therefore, sensing surfaces of sensors can be always in good contact with rock specimen surface, wherein the vacuum grease works as the coupling medium. During the test, the sampling frequency and threshold level of the $\mathrm{AE}$ system were set as $2 \mathrm{MHz}$ and $45 \mathrm{~dB}$, respectively. The vertical indentation force was exerted on the cutter by RMT-301, a servo-controlled testing machine which was developed by the Institute of Rock and Soil Mechanics, Chinese Academy of Sciences. The testing system can automatically record the entire loading process.

3.3. Experimental Setup and Procedure. The main purpose of this study is to investigate the differences of rock fragmentation response under the penetration by different cutter types, so the influence of confining stress level was not considered here. To simulate the real confined state of excavated rock near the tunnel face, equal biaxial stresses were imposed in the comparative test. Rock specimens are, respectively, labelled with "GC5," "GW5," "SC5," and "SW5," where " $G$ " and " $S$ " denote the granite and sandstone specimen, "C" and "W" denote the CCS cutter and V-type cutter, and " 5 " denotes the biaxial confining stress value with the unit "MPa."

After the lateral stress was exerted slowly, the P-wave speed of rock was measured with the AST (auto sensor test) function of the AE system. Then, several iterations of pencil-lead break tests were conducted on the upper surface of the specimen as the method suggested by ASTM [37], to ensure the good sensor-rock coupling and calibrate the AE location accuracy. During the test, the normal indentation force was exerted in the vertical displacement control mode with a speed of $0.005 \mathrm{~mm} / \mathrm{s}$ and the AE activity in rock was recorded synchronously and continuously. The indentation loading would continue for another $3 \mathrm{~mm}$ in penetration depth after major cracks of rock occurred to make the rock failure pattern more obvious.

\section{Experimental Result and Analysis}

4.1. Mechanical Response and AE Characteristics. Figure 7 shows the mechanical and AE responses of different rock specimens penetrated by using CCS and V-type disc cutters. 


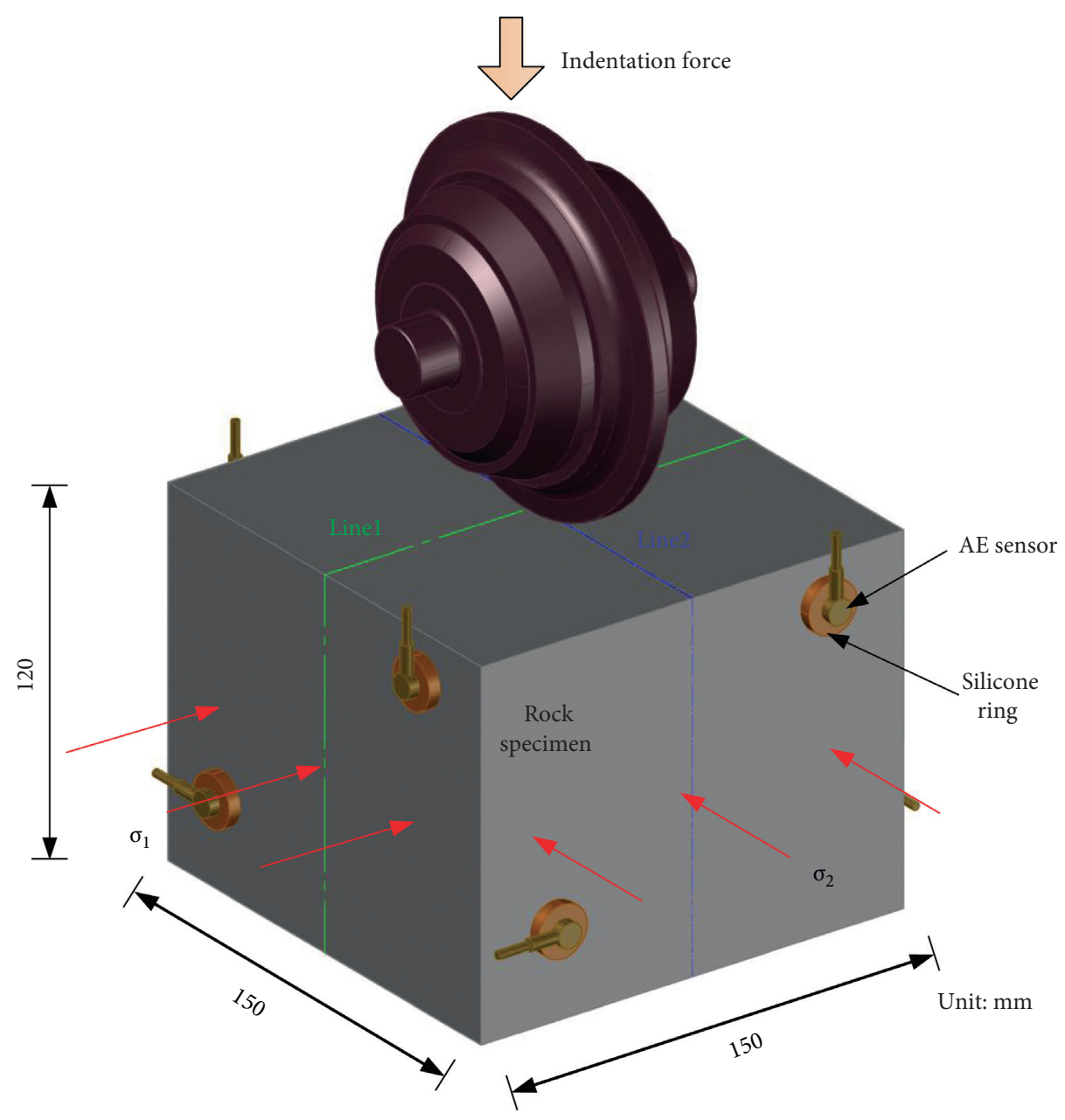

Figure 6: Sketch of stressed rock specimen and AE sensor array.

The fragmentation processes of two rock types, respectively, penetrated by different disc cutters vary significantly.

For granite and sandstone specimens penetrated by using CCS cutter, their typical fragmentation processes and failure patterns are shown in Figures $7(a)$ and $7(b)$ and Figures 8(a) and 8(b). Referring to the experiment conducted by Liu et al. [24], the fragmentation process of the specimen GC5 can be divided into three stages. The first stage is the pre-existing microflaw closure process, and the indentation force increased relatively slowly with little AE activity. When it came to the second stage, the indentation force began to undergo a rapid and linear rise, and increasing AE hits were detected. It can be attributed to the continuous accumulation of rock microcracking and plastic deformation under cutter penetration, and the process corresponded to the formation and expansion of rock damage zone. When stress state of the rock specimen reached the critical condition, i.e., the cracking point in Figure 7 (a), the major crack occurred accompanied by the violent cracking sound and the sudden burst of AE energy. Some macrocracks propagated from the vicinity of the central crater under the cutter and approximately developed along Line 2 in Figure 6. However, no sharp force drop at the cracking point was observed due to the existence of lateral confinement. After that, the forcepenetration curve entered a repeated rise-drop stage which reflected the further rock fragmentation induced by CCS cutter penetration. The fragmentation process of the specimen SC5 has a similar phase feature, but a local rock chip formation occurred before the cracking point and brought about a small force drop and local leap of AE hits. Compared with the granite specimen, the damage accumulation process in sandstone is characterized by continuous AE energy release, instead the former undergoes an initial silent period and an abrupt AE energy release at the cracking point. It can be attributed to the higher brittleness of the granite than that of the sandstone under the present confinement. In the failure pattern, two types of rocks indented by using the CCS cutter are both characterized by the sequential formation of the fragmentized crater and extended major cracks with few local rock chips formation.

The rock fragmentation mechanism by using the CCS cutter can be well explained in Figure 4. In the rock indentation test, the crushed zone under the CCS cutter is in the triaxial compression state. Rock in the crushed zone bears the normal pressure $\sigma_{1}$ exerted by the cutter penetration, and the surrounding is constrained by the confining 


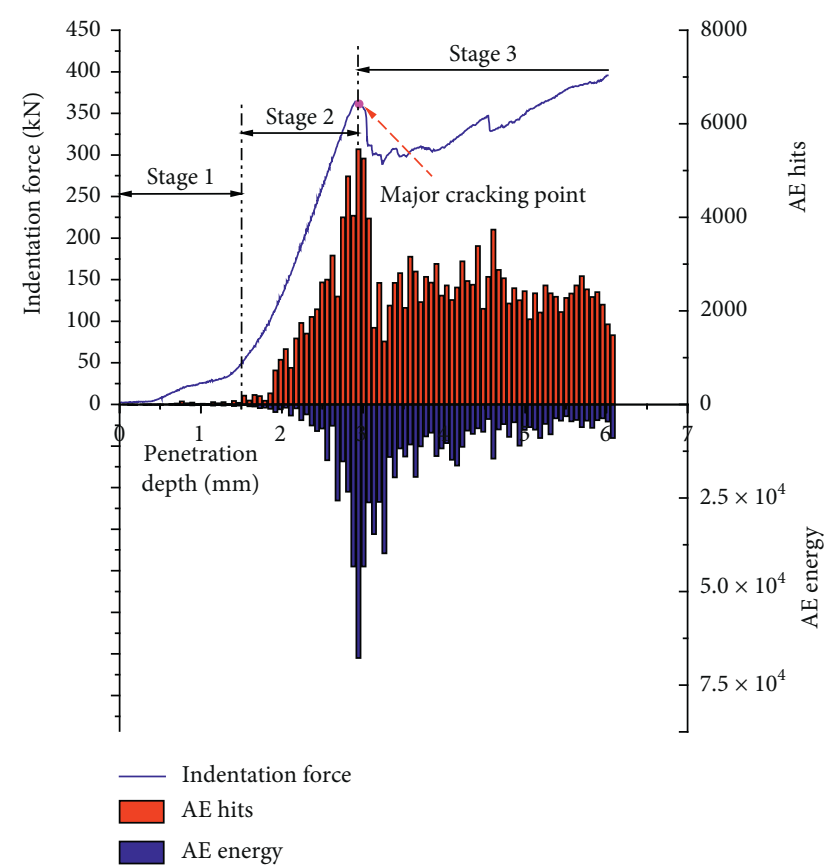

(a)

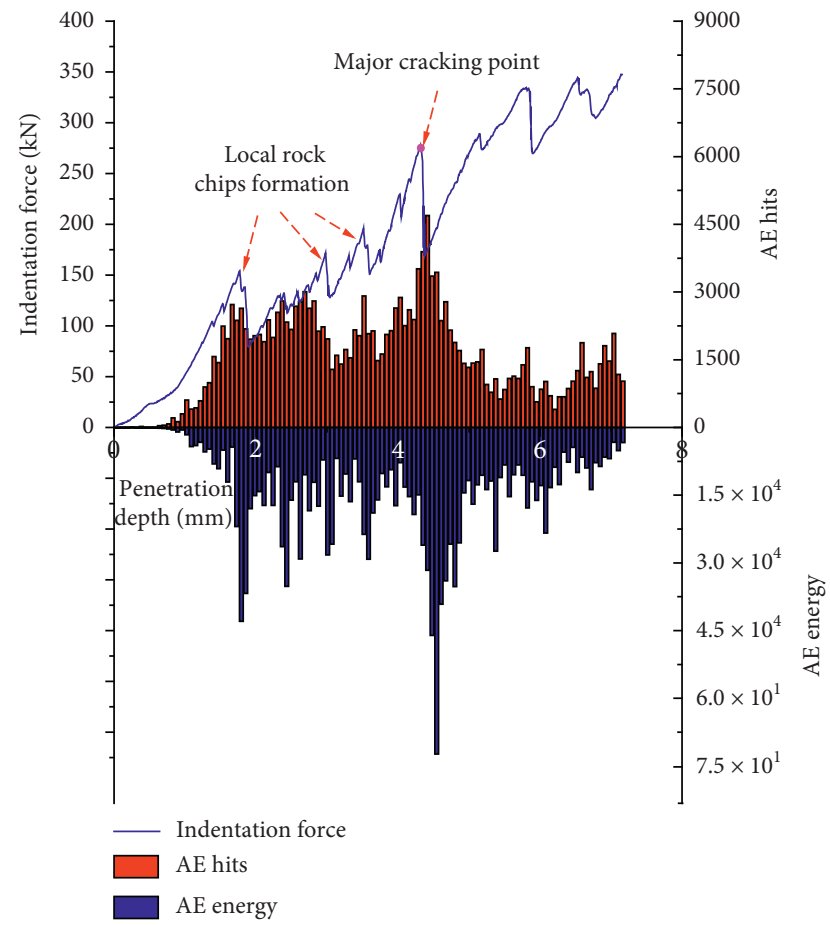

(c)

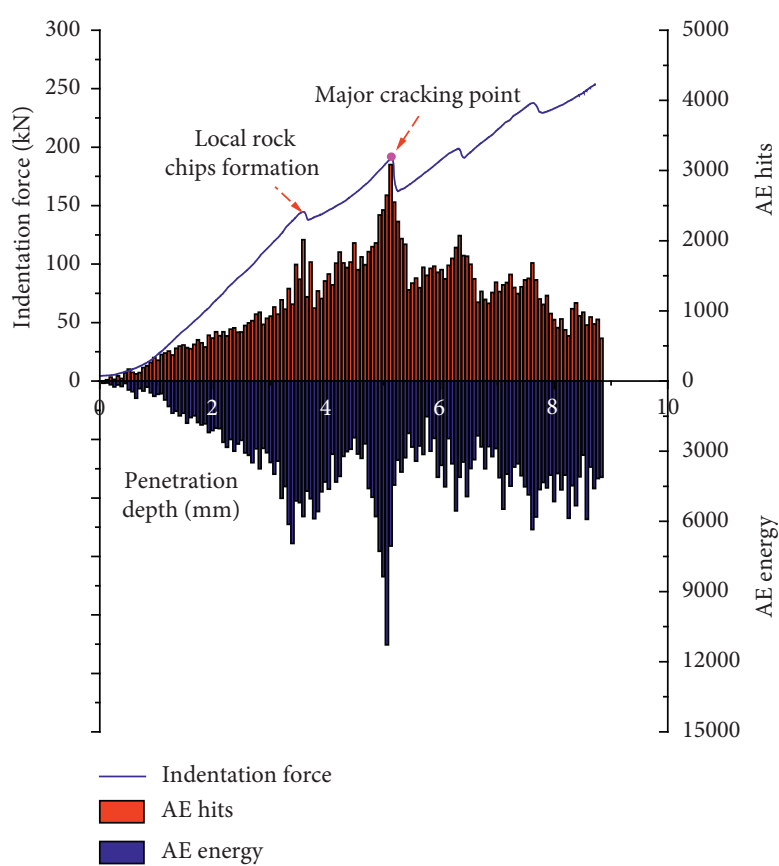

(b)

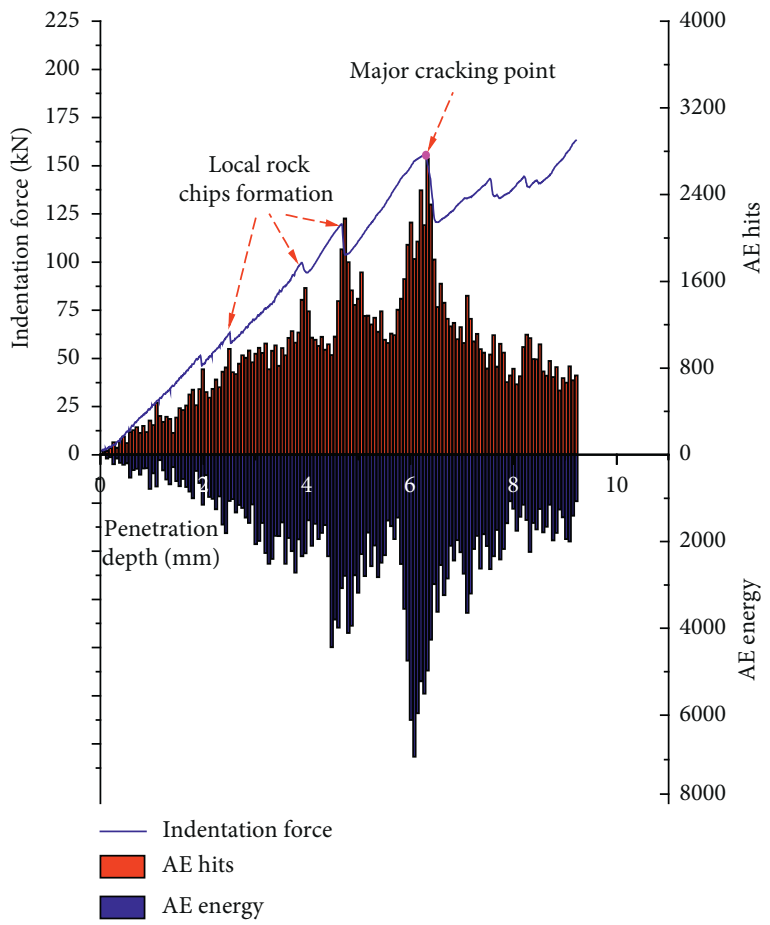

(d)

FIGURE 7: Mechanical and AE responses of different rock specimens penetrated by different cutter types: (a) GC5; (b) SC5; (c) GW5; (d) SW5.

stress $\sigma_{2}=\sigma_{3}=\sigma_{0}$. The normal stress $\sigma_{1}$ increases gradually with the increasing penetration by using the disc cutter. When its stress state reaches the yield criterion such as the Mohr-Coulomb strength criterion, the shear failure occurs. Accompanied by continuous cutter penetration, rock mass in the crushed zone repeatedly reaches the yield condition and severe compression-shear fragmentation occurs again and again. Numerous shear fracture faces cut the rock into extremely small particles or even powders. The CCS cutter transfers the indentation force to the pressure on surrounding rock through taking the crushed rock, which consists of fine rock particles developed by high compaction stress immediately under the cutter, as the force medium [31]. 


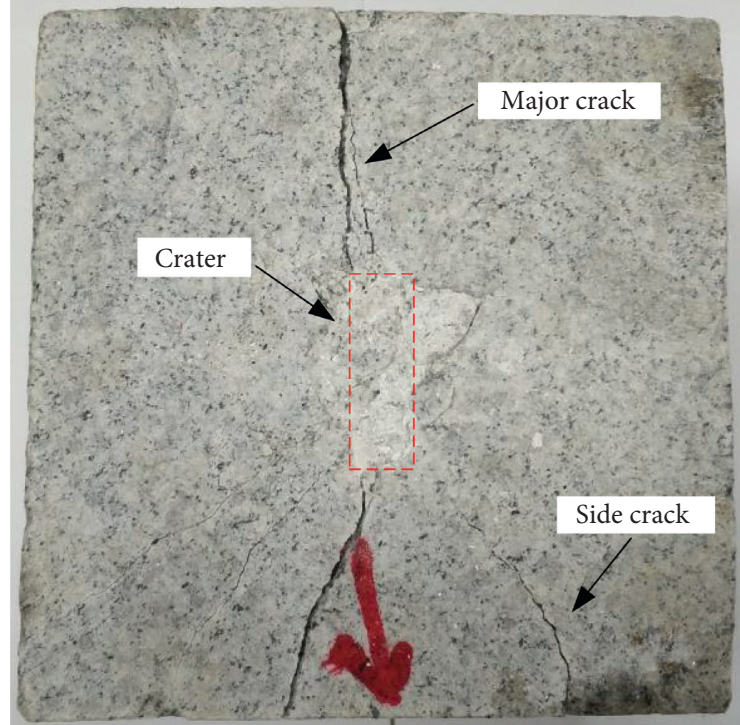

(a)

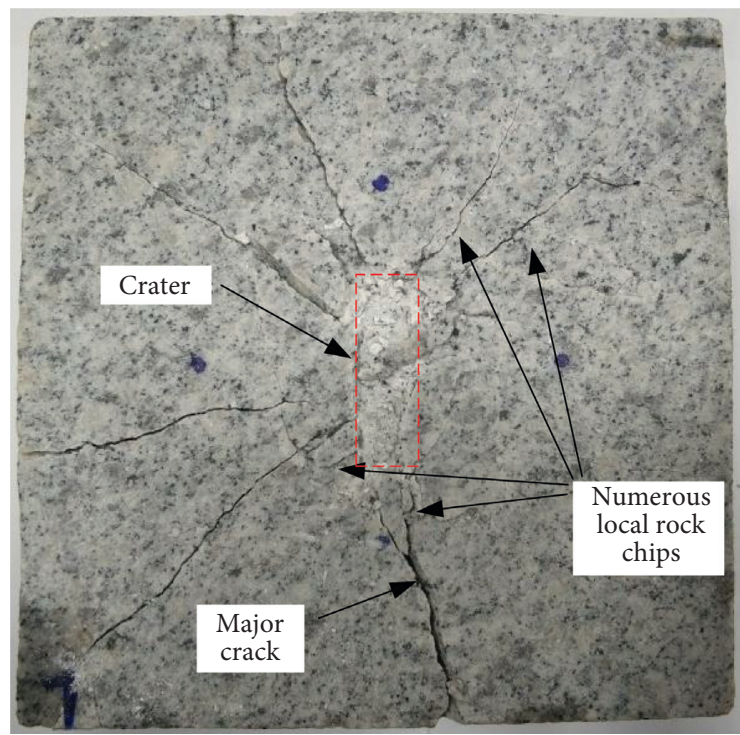

(c)

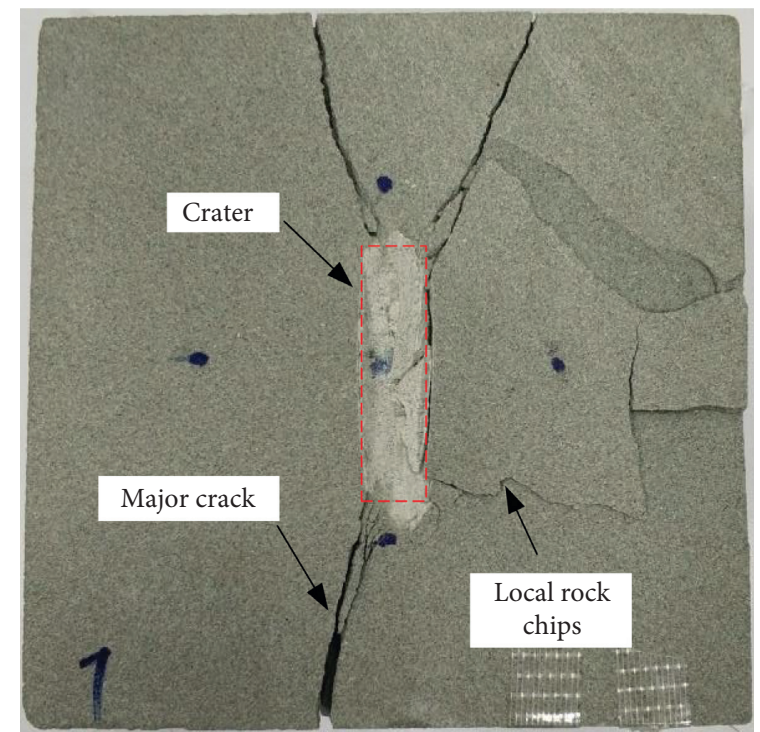

(b)

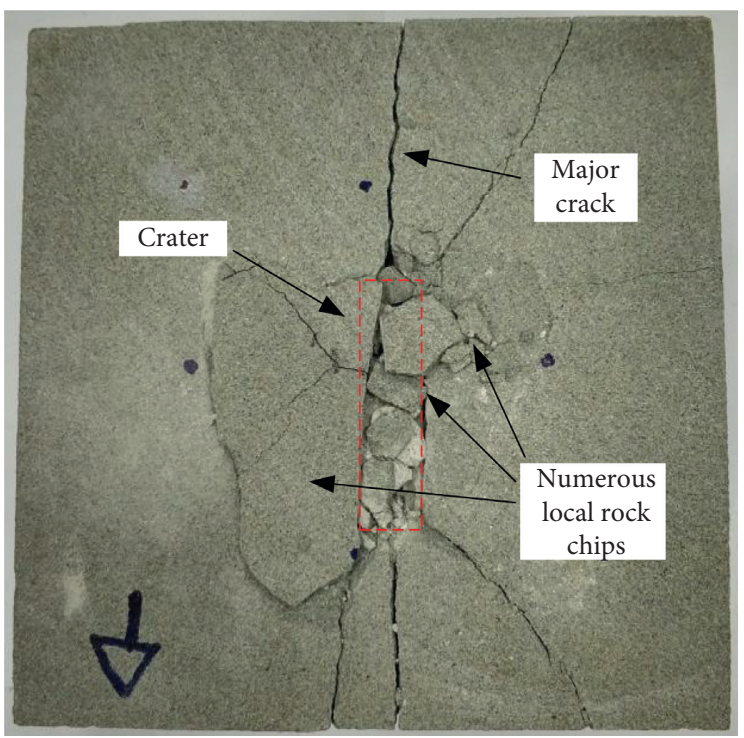

(d)

FIGURE 8: Fragmentation pattern of different rock specimens penetrated by different cutter types: (a) GC5; (b) SC5; (c) GW5; (d) SW5.

Differently, the specimens penetrated by using the V-type cutter experienced multiple local rock chips formation before the major cracking points for both granite and sandstone (shown in Figures 8(c) and 8(d)), and it resulted in the sawtooth force-penetration curve (shown in Figures 7(c) and 7(d)). The simplified wedge indentation model proposed by Paul and Sikarskie [38] is illustrated in Figure 9, and it can be used to explain the rock fragmentation induced by using the V-type cutter. As the V-type cutter penetrates the rock surface, the stress field builds under the cutter until rock chip formation and quick force drop. It is thought that the side force transferred from the indentation force causes the shear failure and local rock chips formation when the rock stress state on the slide surface reaches the critical Mohr-Coulomb failure criterion. After that, the V-type cutter continues to penetrate rock and causes new chip formation and force variation. It is mainly the lateral extrusion effect of the V-type cutter that results in a high tendency of local rock fragmentation and rock chips formation [39, 40]. Meantime, the amplitude of local force drop of sandstone is significantly lower than that of granite due to their differences in brittleness-ductility characteristics.

Rock fragmentation processes of comparative tests indicate that the CCS cutter tends to cause the inconspicuous chips formation before the sudden occurrence of macrocrack, instead the V-type cutter tends to induce the gradual fragmentation with the multiple local rock chips formation. On the other hand, the high-frequency variation of V-type cutter thrust during the cutter penetration can intensify the force unbalance of cutterhead and cause its violent vibration, which can further aggravate the cutter wear and its abnormal rupture and decrease the excavation efficiency of TBM. It is 


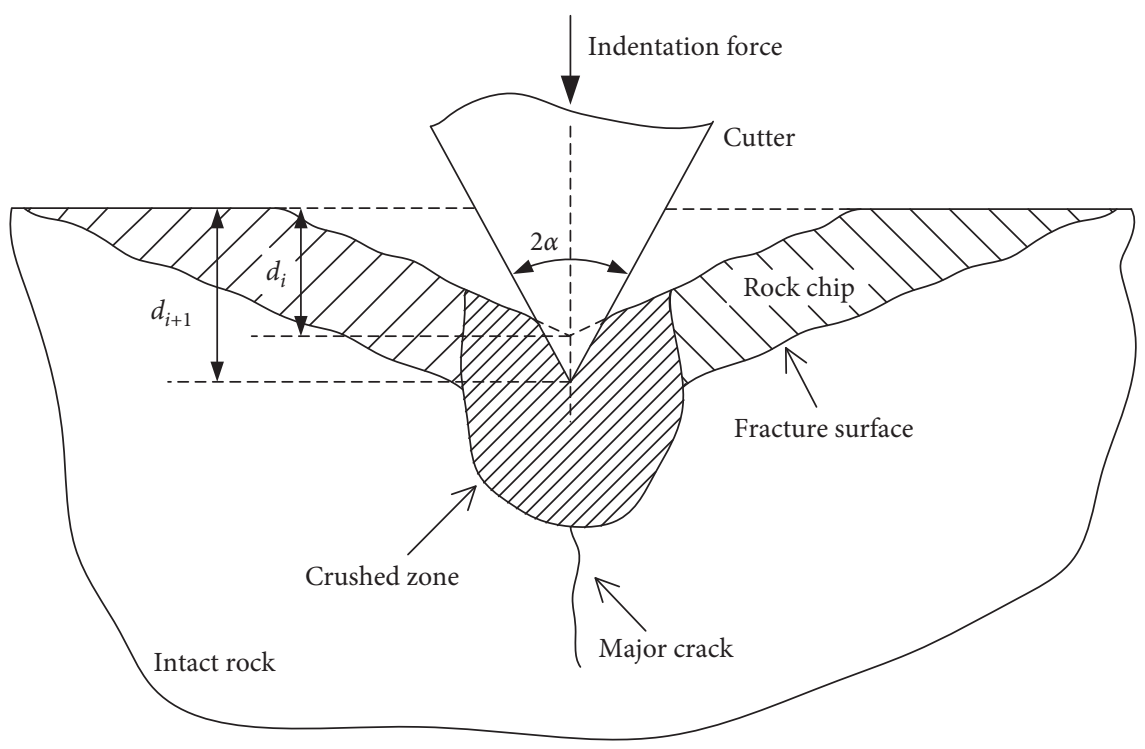

FIgURE 9: Postulated failure geometry proposed for the ith chip [38].

also an important reason for high consumption rate of the V-type cutter besides its less wear capacity and shorter service life $[33,41]$.

For rock excavation with disc cutters, the reasonable cutting parameters should equal or exceed the critical indentation force or penetration depth of rock at the cracking point, which can induce the macrocrack occurrence and voluminal fragmentation in rock. The indentation forces and penetration depths at cracking points of rock specimens are listed in Table 2. Their ratio can be used to define a characteristic value, i.e., penetration coefficient " $K$," to approximately reflect the unit resistance of rock when penetrated by a specified cutter. It can be found that the rock penetrated by using the CCS cutter shows greater indentation force but lower penetration depth at the cracking point than those penetrated by using the V-type cutter. Therefore, when penetrating the same rock, the value of $\mathrm{K}$ for the CCS cutter is also much larger than that for the $\mathrm{V}$-type cutter. This comparison indicates that the V-type cutter has greater penetration ability in rock, and it is why in some projects with very hard rock, the CCS disc cutters have to be replaced with $\mathrm{V}$-type disc cutters despite the expected high cutter wear. The V-type disc cutter can reduce the required thrust of TBM and get enough and efficient penetration depth per cutterhead revolution [17, 27, 29, 41, 42].

Figure 10 shows the typical inner damage zone range of the rock specimen SW5 after indentation. A crater composed of compacted rock powder and surrounded by rock chips spalling was formed due to the strong local compaction stress under cutter penetration. In the major crack face, the crushed zone can be easily distinguished due to its obvious boundary with the intact zone of rock. When the development of crushed zone reached the critical state, major cracks initiated and propagated from its boundary. Research about formation characteristics of the crushed zone is meaningful for deep understanding of rock fragmentation mechanism and effective evaluation of the cutting energy utilization. Meanwhile, the fracture morphologies of the crushed zone and the major crack face are obviously different, which implies the possible differences of them in the microscopic mechanical mechanism. It is further explored in a later section.

\subsection{Damage Zone Analysis Based on AE Events Distribution}

4.2.1. AE Location Method. AE events development can reflect the damage evolution process in rock during the cutter penetration. In order to quantitatively evaluate rock damage zone range based on the $\mathrm{AE}$ events distribution, an efficient and precise location method is essential.

$\mathrm{AE}$ activity induced by rock microcracking during the cutter penetration is considerably intense, especially when approaching the cracking point. Traditional methods usually use criteria like event definition value (EDV) and event lockout value (ELV) to determine $\mathrm{AE}$ waveforms of the same hypocenter. However, they may bring about some severe location errors due to the inaccurate waveform selection. Chen et al. [43] proposed an improved AE source location method which combined the automatic determination of P-wave arrival time based on the Akaike information criterion (AIC) with the waveform identification based on similarity assessment technique. The method proved efficient in eliminating those interference and invalid signals and improving location accuracy and reliability. This method was also employed in the present study, especially only five waveforms sharing the highest similarity in the same receiving period were selected for the location calculation of an $\mathrm{AE}$ event.

Meanwhile, the simplex method [44], an iterative location algorithm with high speed and reliability was also employed and its principle sketch is shown in Figure 11 [45]. Four initial iteration points A, B, C, and W are compared with each other in error value which is defined as the calculated variance of occurrence time of the $\mathrm{AE}$ 
TABLE 2: Values of mechanical response at cracking points.

\begin{tabular}{lccc}
\hline Rock specimens & $\begin{array}{c}\text { Indentation force } \\
\mathrm{kN}\end{array}$ & $\begin{array}{c}\text { Penetration depth } \\
\mathrm{mm}\end{array}$ & $\begin{array}{c}\text { Penetration coefficient K } \\
\mathrm{kN} / \mathrm{mm}\end{array}$ \\
\hline GC5 & 364.26 & 2.906 & 125.35 \\
GW5 & 286.14 & 4.521 & 63.29 \\
SC5 & 190.98 & 5.150 & 37.08 \\
SW5 & 155.76 & 6.290 & 24.76 \\
\hline
\end{tabular}

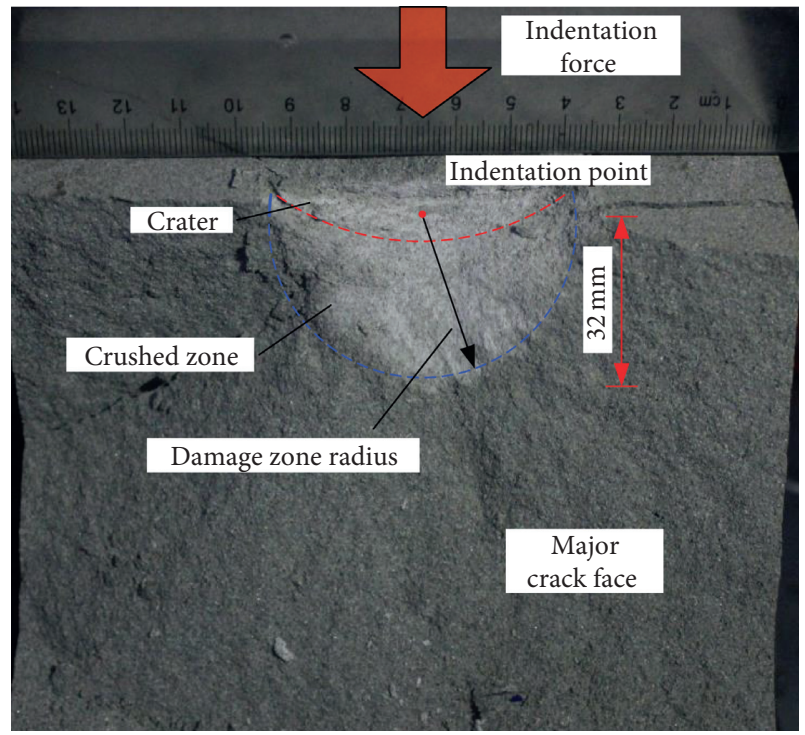

FIGURE 10: Inner damage zone range of the rock specimen SW5 after indentation.

event based on detections of different sensors as equation (3). Wherein, $\mathbf{x}$ is the object point, $\mathbf{x}_{i}$ is the sensor position, $t_{i}$ is the $\mathrm{P}$-wave arrival time of the sensor, $v_{p}$ is the velocity of the $\mathrm{P}$-wave, $\bar{t}$ is the average value of calculated occurrence time of $\mathrm{AE}$ event based on detections of different sensors as equation (4), and $N$ is the number of selected waveforms. These four points can eventually shrink into a tiny region after multiple symmetry, expansion, and contraction transformations according to their error values, and the geometric center of the tiny region is determined as the hypocenter location [46].

$$
\begin{aligned}
f(\mathrm{x}) & =\frac{1}{N} \sum_{i=1}^{N}\left(t_{i}-\frac{\left|\mathrm{x}_{i}-\mathrm{x}\right|}{v_{p}}-\bar{t}\right)^{2} . \\
\bar{t} & =\frac{1}{N} \sum_{i=1}^{N}\left(t_{i}-\frac{\left|\mathrm{x}_{i}-\mathrm{x}\right|}{v_{p}}\right) .
\end{aligned}
$$

With the combination of the aforementioned methods for $\mathrm{P}$-wave onset determination, waveform selection, and hypocenter location, AE source location can be obtained with high accuracy. Through the validation of pencil-lead break tests, it is indicated that the mean location error of $\mathrm{AE}$ events is within $5 \mathrm{~mm}$ for the intact specimens, which meets the precision requirement for quantitative analysis.
4.2.2. Damage Evolution Process. Taking the case of rock specimen SW5, the evolution sequence of accumulated AE events under cutter penetration is shown in Figure 12 in colored scatter diagrams. Figures, respectively, correspond to $20 \%, 40 \%, 60 \%, 80 \%, 100 \%$, and $120 \%$ of the cutter penetration depth at its cracking point (shown in Figure $7(\mathrm{~d})$ ). The point color of the AE event represents its energy, i.e., those close to red represent the high energy level and those close to blue are adverse.

Initially (Figure 12, 20\%), some microcracks occurred and clustered under the cutter due to stress concentration. It corresponds to the initiation of the damage zone. With the further increase in cutter penetration (Figure 12, 40\%-80\%), more $\mathrm{AE}$ events were observed below the cutter, and the $\mathrm{AE}$ events clustering zone also gradually expanded. It indicates that as the cutter penetration increased, the damage zone range and rock deterioration degree inside the rock developed continuously and more mechanical energy accumulated inside was released or transformed into other types, like wave energy and surface energy of newly formed microcracks. A significant clustering zone of AE events with high energy was observed just underneath the cutter, which corresponded to the highly fractured zone well formed under the strong local compaction. Meanwhile, some AE events were also located far from the center of the damage zone during the cutter penetration. The discrete microcracking in the specimen can be mainly attributed to the rock property heterogeneity. When the stress field in rock reached the critical state (Figure 12, 100\%), the major cracks occurred from the damage zone under the continuous promotion of indentation force. At the cracking point, the dramatic increase in $\mathrm{AE}$ activity was recorded due to the release of stress-strain energy accumulated in rock. Although the number of located $\mathrm{AE}$ events continued increasing after the major cracks occur, their location errors would also increase theoretically because of the adverse effect of major crack faces on the acoustic transmission, including energy attenuation, waveform change, wave velocity effect, and so on. Therefore, after the major cracks occur, it may be no longer suitable to quantitatively analyze the damage development of rock based on the spatiotemporal evolution of $\mathrm{AE}$ events.

4.2.3. Damage Zone Analysis. The damage zone size can be quantitatively estimated based on AE cluster distribution characteristics in rock indentation tests [1]. As shown in Figure 13, the statistical hemisphere model was proposed and the relative analysis based on AE events distribution was conducted to determine the rock damage zone size. The 


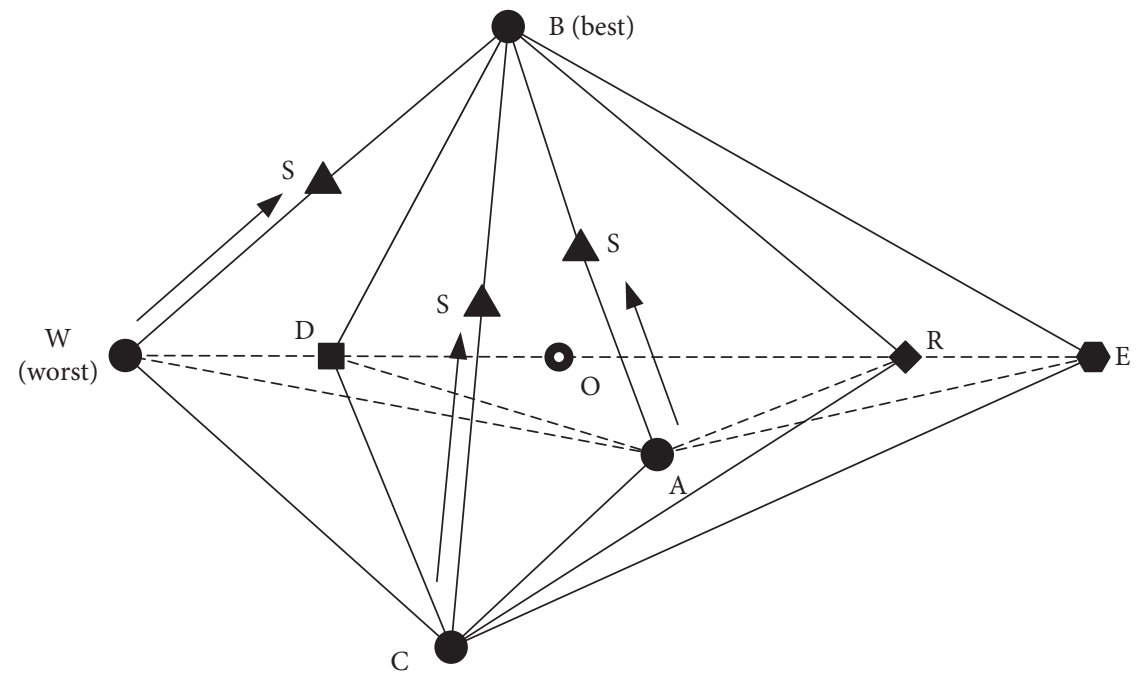

FIGURE 11: Schematic graph of the simplex method [45].

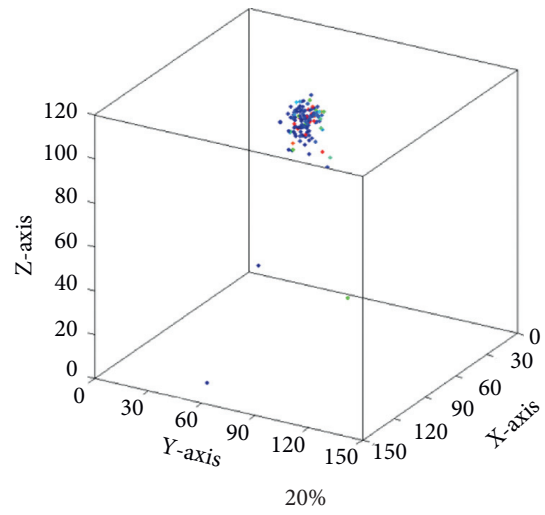

(a)

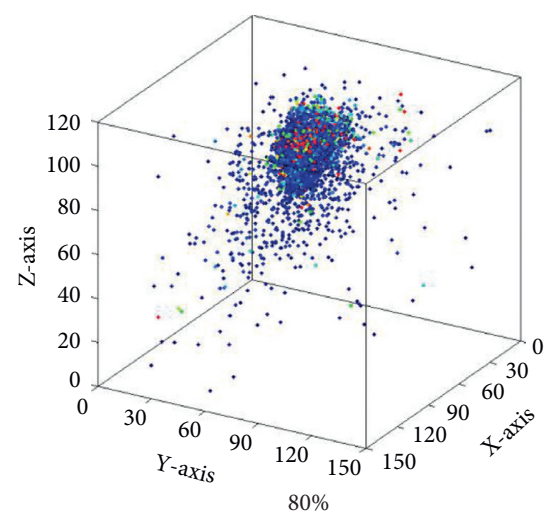

(d)

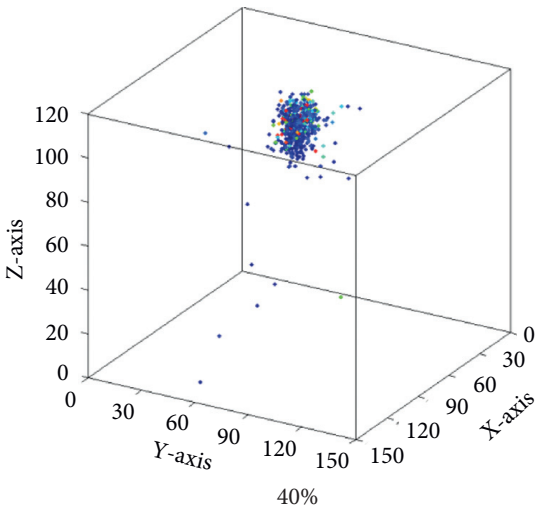

(b)

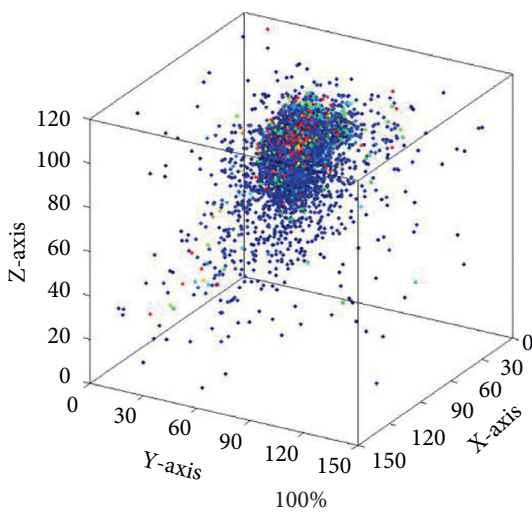

(e)

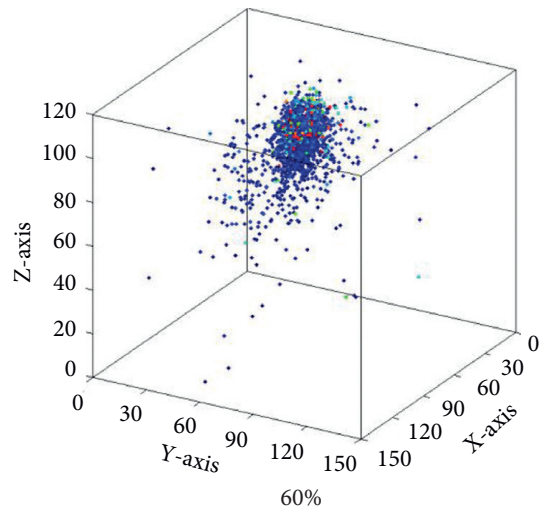

(c)

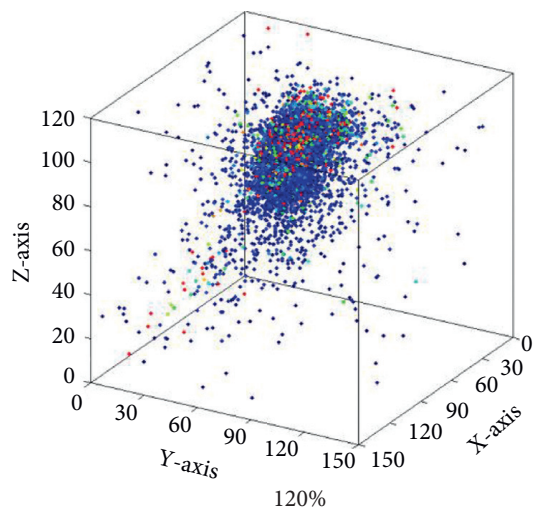

(f)

FIGURE 12: Evolution sequence of the accumulated AE events of specimen SW5 under cutter penetration (the percentage denotes different loading stage, i.e., the ratio of current penetration depth to that at the cracking point): (a) $20 \%$; (b) $40 \%$; (c) $60 \%$; (d) $80 \%$; (e) $100 \%$; (f) $120 \%$.

statistical hemisphere at the indentation loading point has a radius of SR (statistical radius), and all AE events located in the hemisphere are counted. With the increasing statistical radius, more and more events can be included and the curve between the number of counted $\mathrm{AE}$ events and the statistical radius can be obtained.
Figure 14 shows the number-radius curves for the typical rock specimen SW5 at different indentation stages. It can be found that all curves undergo a similar changing process, i.e., a rapid and linear rise stage at the beginning which means massive $\mathrm{AE}$ events were formed around the indentation point and a following slow growth stage when the statistical 


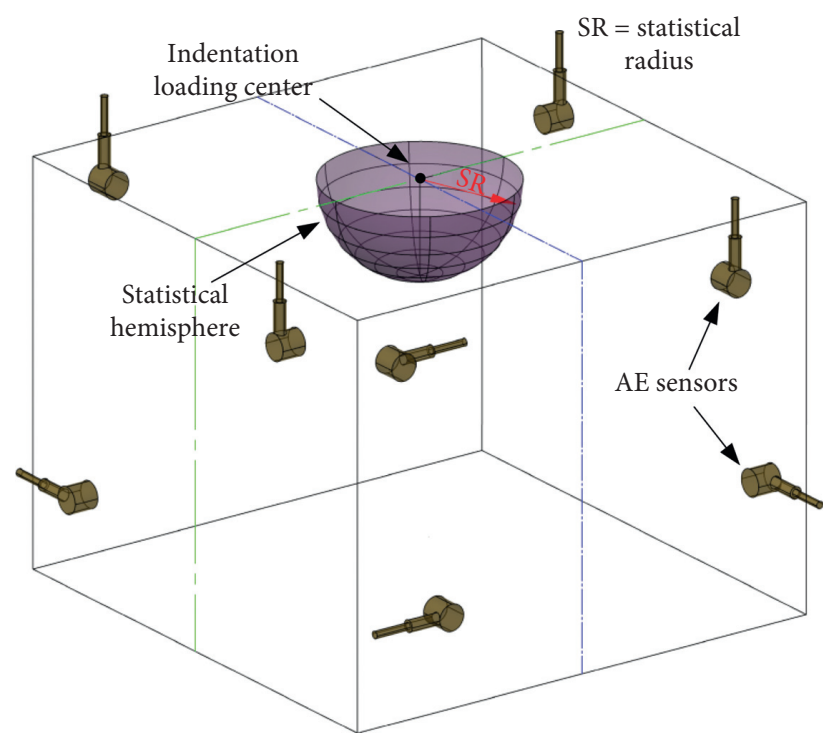

Figure 13: The determination model for damage zone size.

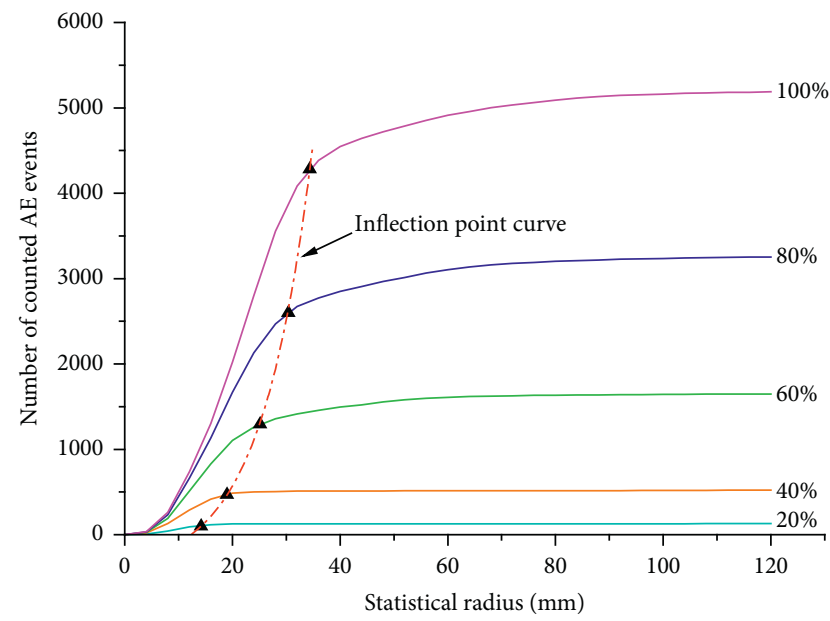

FIGURE 14: Relationship curves between the number of counted AE events and the statistical radius for SW5 at different loading stages (the percentage denotes the ratio of current penetration depth to that at the cracking point).

radius further increases and exceeds the damage zone range. The abscissa value of curve inflection point gradually increases with the increasing cutter penetration, and it can be approximately regarded as the radius of rock damage zone. The value can be quantitatively determined according to the intersection between the tangent line of the linear growth segment and that of slow growth segment (shown in Figure 15). The estimation value for the damage zone radius of specimen SW5 at the cracking point is $33.03 \mathrm{~mm}$ which is very close to the actual measured value of $32 \mathrm{~mm}$ in Figure 10, indicating that the above estimation method is effective. The fitting result of rock damage zone radius development with cutter penetration is shown in Figure 16, and there exists an exponential function relationship with a negative coefficient between them. With the increasing cutter penetration depth, the range of the rock damage zone

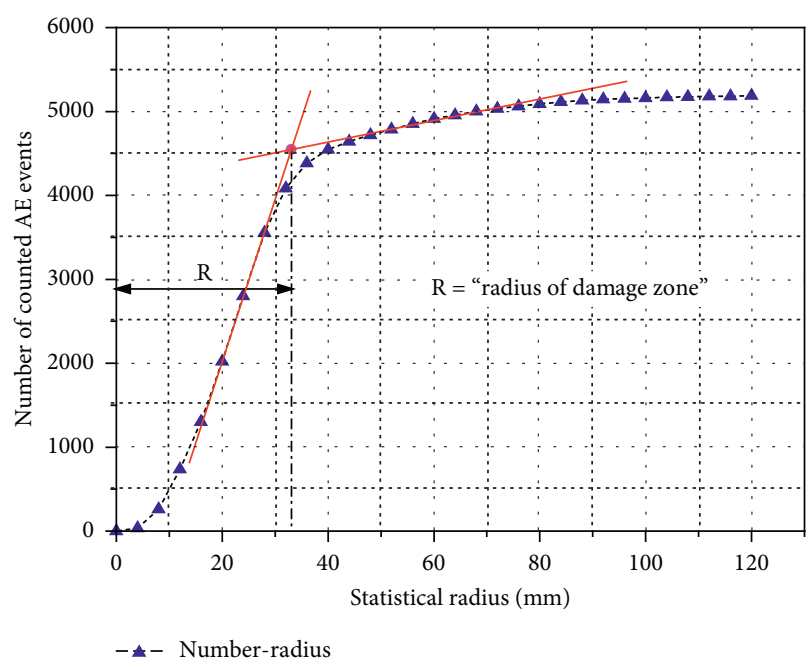

FIgURE 15: Quantitative determination for damage zone size based on statistical result of $\mathrm{AE}$ events distribution at the cracking point.

gradually expands and rock fragmentation degree is also deepened. The penetration work of disc cutters is mainly transformed into the plastic work for the formation of the crushed zone and disintegrated rock chips.

Similar statistical analyses are conducted for other specimens and the quantitative estimation results are shown with a histogram in Figure 17. Because the major cracks of different specimens occurred at different penetration depths, a characteristic parameter, unit damage zone radius was defined as the ratio of the damage zone radius to penetration depth at the corresponding cracking point to evaluate the damage zone characteristics of rocks penetrated by different cutter types. From Figure 17, it can be found that the unit damage zone radius of rock induced by using the CCS cutter is larger than that induced by using a V-type cutter for the same rock. Larger unit damage zone 


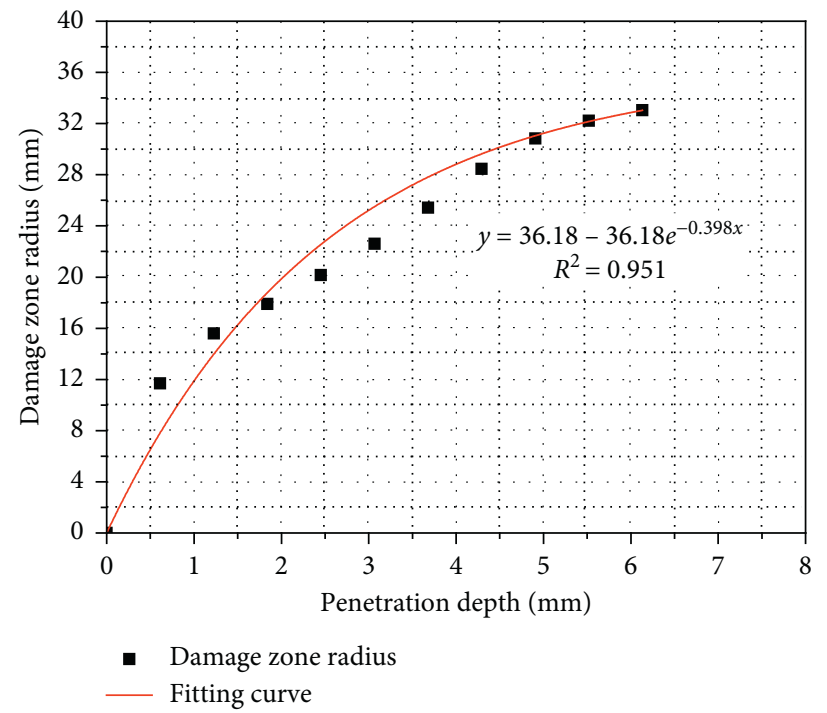

FIGURE 16: Damage zone radius development for SW5 before the cracking point.

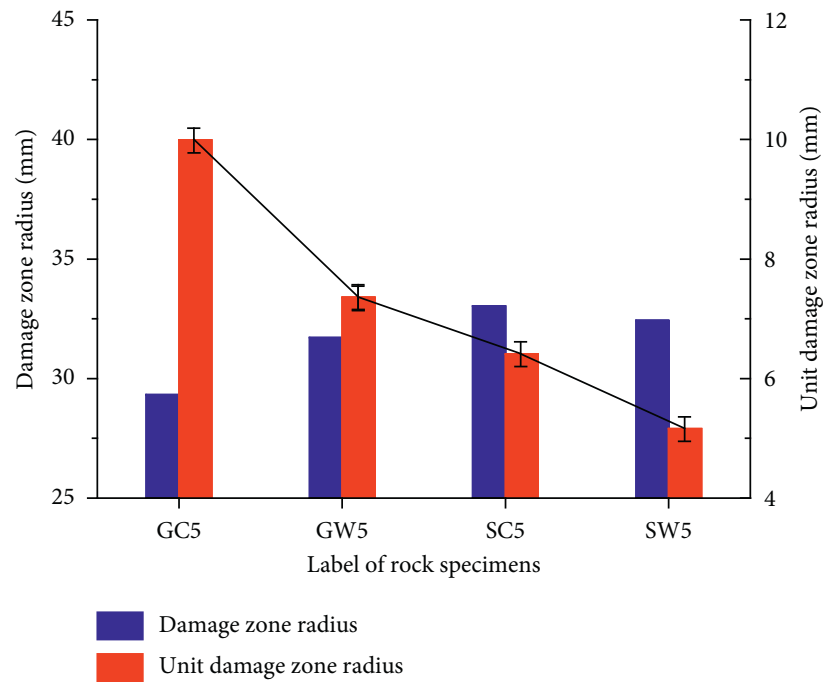

FiguRe 17: Result of damage zone radius and unit damage zone radius of different specimens at the cracking points.

radius means that more energy is consumed for damage zone development without regard to damage degree differences, and thus relatively less energy can be stored for macrocracks and effective rock chips formation when penetrating in the same depth using the CCS cutter than that using the V-type cutter. Similarly, Figure 8 also supports that more side cracks and rock chips are generated during the penetration by using the V-type cutter than that by using the CCS cutter with the same cutter width, which contributes to higher rock cutting efficiency. Meanwhile, the unit damage zone radius in hard rock (granite) is also greater than that in relatively soft rock (sandstone) when penetrated by the same cutter. It means the crushed zone develops faster in hard rock than that in relatively soft rock with unit penetration depth although more penetration work is needed in hard rock due to its stronger mechanical resistance. However, despite the better mechanical energy utilization and higher formation trend of side cracks for rock cutting using the V-type cutter, most tunnel excavations have to choose the CCS disc cutters in consideration of their longer service life and greater wear capacity for cutting abrasive rock $[28,36]$. How to comprehensively consider the thrust requirement, cutting efficiency, and service life is still a problem in the current design, manufacture, and application of disc cutters.

4.3. SEM Observation for Fracture Faces of Different Rock Damage Zones. Scanning electron microscope (SEM) observations were conducted on typical fracture faces of failed rocks as shown in Figures 18 and 19, aiming to intuitively obtain their microscopic morphology feature. Figures 18(a) and 18(b) are sampled from the crushed zones, and Figures 18(c) and 18(d) are sampled from the major crack faces of granite specimens GC5 and GW5, respectively. Figure 19 also corresponds to similar sampling positions for 


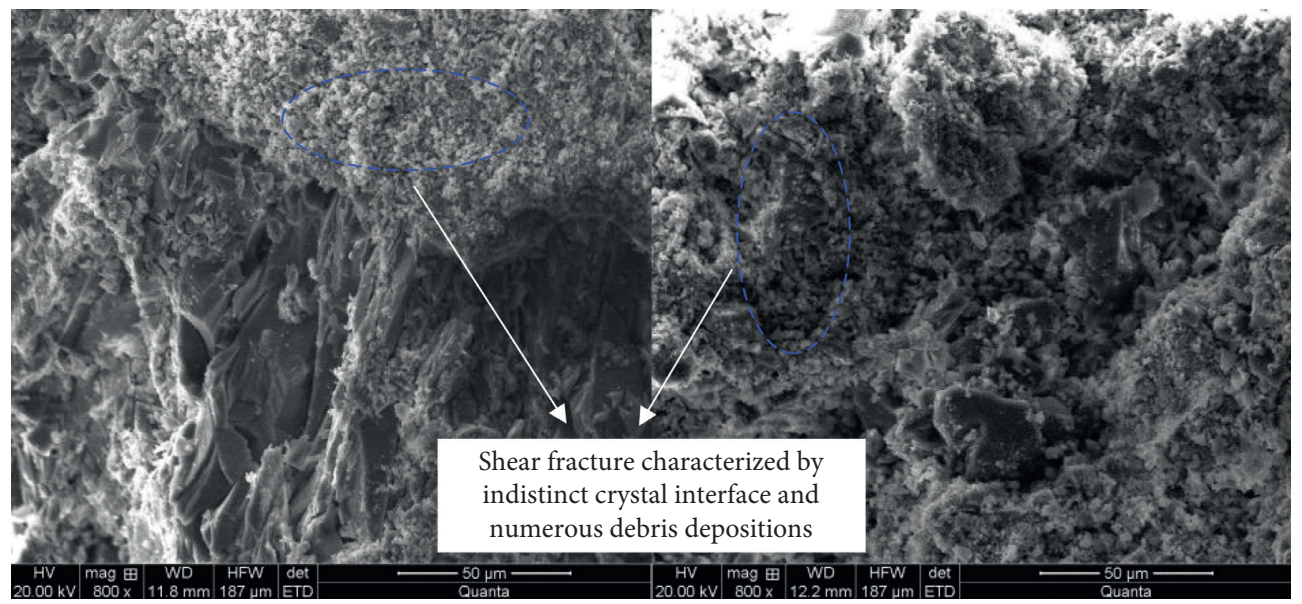

(a)

(b)

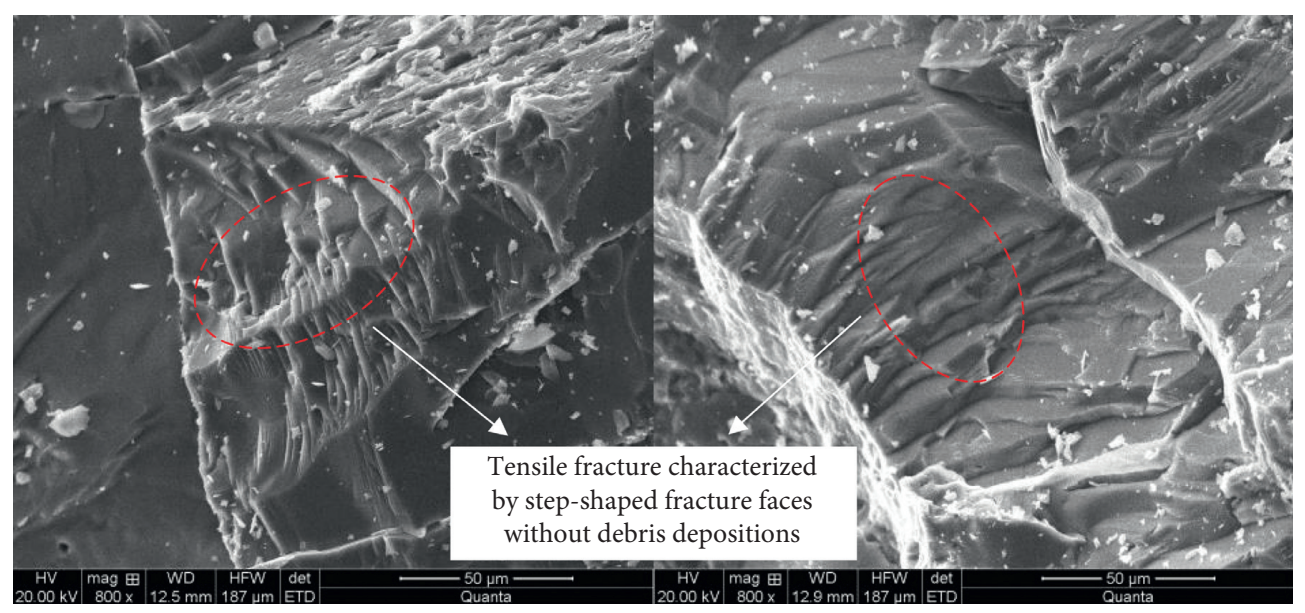

(c)

(d)

Figure 18: SEM images of granite fracture faces: (a), (b) sampled from the crushed zones and (c), (d) sampled from the major crack faces of specimens GC5 and GW5, respectively.

sandstone specimens SC5 and SW5. It can be found that the microscopic morphology features of fracture faces sampled from different rock damage zones vary significantly. To connect the microcracking mechanism with the macroscopic fracture analysis of rock, Tan [47] and Liu and Lee [48] classified the mechanical mechanisms of fracture faces of rock into three types based on their microscopic morphology features observed by using SEM, i.e., the tensile, the shear, and the mix-mode. The above classification method was also applied in this study.

As shown in Figures 18(a) and 18(b), the fracture faces sampled from crushed zones of granite specimens are characterized by numerous debris depositions and indistinct crystal interface (the blue ellipses). Similarly, for Figures 19(a) and 19(b), the fracture faces sampled from crushed zones of sandstone specimens show that there are numerous dense debris depositions around the fractured steps (the blue ellipses). It is the microscopic representation of rock crystal fragmentation under severe and repeated compression-shear failure. In contrast, for
Figures 18(c) and 18(d) sampled from major crack faces, obvious step-shaped fracture faces without debris depositions (the red ellipses) are observed and they are caused by tensile stress due to the splitting motion when the macrocrack occurs. Figure 19(c) shows the typical conchoidal fracture (the red ellipse) which is induced by the tensile fault of clay matrix cement between crystals of sandstone, and Figure 19(d) can be also determined as the tensile type according to its obvious step-shaped fracture faces (the red ellipse).

From the above analysis about microscopic observations of fracture faces sampled from different fracture zones of different rock specimens, it can be concluded that the fracture mechanism for the crushed zone of rock is mainly shear type due to the great compressive stress under cutter penetration and that for the major crack is tensile type due to the splitting motion accompanied by the occurrence of major cracks. In indentation tests, fracture mechanisms of rock in different damage zones do not matter with rock types or cutter types. 


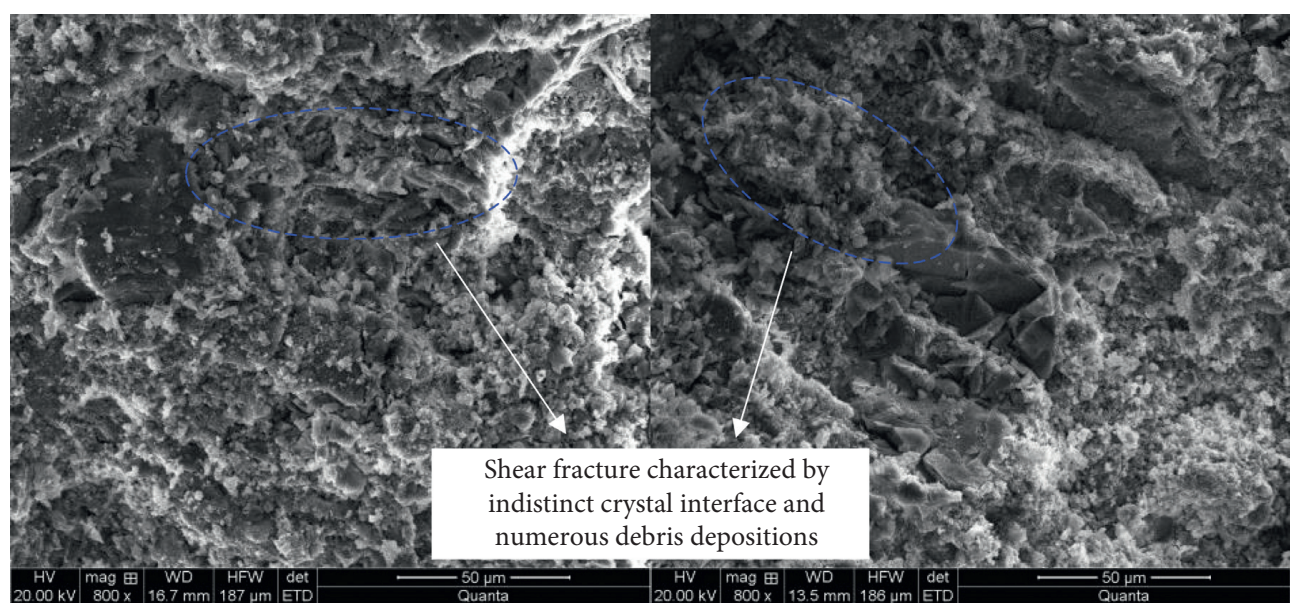

(a)

(b)

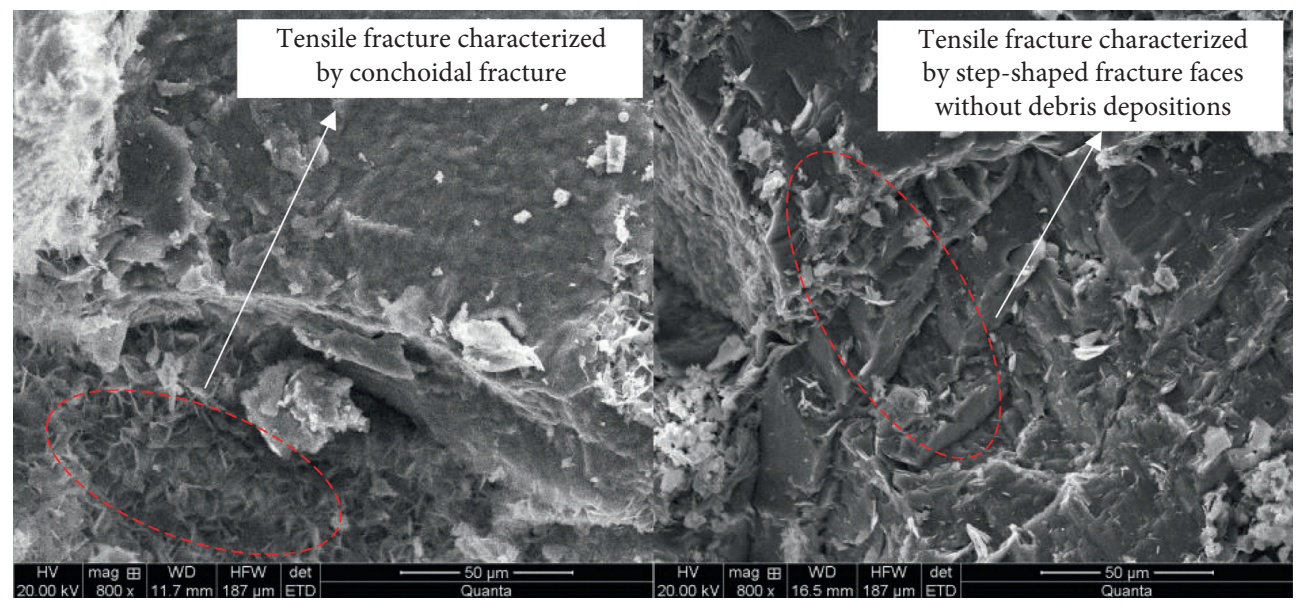

(c)

(d)

FIGURE 19: SEM images of sandstone fracture faces: (a), (b) sampled from the crushed zones and (c), (d) sampled from the major crack faces of specimens SC5 and SW5, respectively.

\section{Conclusions}

Through a set of three-dimensional indentation tests with real-time $\mathrm{AE}$ monitoring, this study investigated the rock fragmentation responses under the penetration by different disc cutters types. Besides the mechanical response and $\mathrm{AE}$ parameter analysis, quantitative estimation for rock damage zone development based on the spatio-temporal evolution of AE events and fracture mechanism analyses based on SEM observations were also conducted. The main conclusions are as follows:

(i) Rock fragmentation response under V-type cutter penetration is significantly different from that under CCS cutter. The penetration by using the CCS cutter tends to cause the inconspicuous chips formation before the sudden occurrence of macrocrack, but that by using the V-type cutter tends to induce gradual rock fragmentation with the multiple local rock chips formation and the sawtooth force-penetration curve. Meanwhile, the V-type cutter shows greater penetration ability in rock than the CCS cutter due to its smaller penetration coefficient. (ii) The evolution process of accumulated AE events can reflect the rock damage zone development under cutter penetration well. Quantitative estimation based on statistical AE events distribution indicates that the unit damage zone radius induced by using the CCS cutter is larger than that induced by using the V-type cutter for the same rock, which means that more energy is consumed for the damage zone without regard to damage degree differences development and thus relatively less energy can be stored for macrocracks and effective rock chips formation when penetrating in the same depth using the CCS cutter than that using the V-type cutter.

(iii) SEM observations of rock fracture face intuitively reveal that the fracture mechanism for the crushed zone of rock is mainly shear type due to the great compressive stress under cutter penetration and that for the major crack is tensile type due to the splitting motion accompanied by the occurrence of major cracks. It does not matter with rock types or cutter types. 


\section{Data Availability}

The data used to support the findings of this study are included within this article.

\section{Conflicts of Interest}

The authors declare that they have no conflicts of interest.

\section{Acknowledgments}

The authors are grateful to the scholars who have contributed to this field of study. This work was supported by the CRSRI Open Research Program (grant no. CKWV2019741/ KY) and China Postdoctoral Science Foundation (grant no. 2019M662568).

\section{References}

[1] L. H. Chen and J. F. Labuz, "Indentation of rock by wedgeshaped tools," International Journal of Rock Mechanics and Mining Sciences, vol. 43, no. 7, pp. 1023-1033, 2006.

[2] M. Entacher, E. Schuller, and R. Galler, "Rock failure and crack propagation beneath disc cutters," Rock Mechanics and Rock Engineering, vol. 48, no. 4, pp. 1559-1572, 2015.

[3] Q. Liu, X. Huang, Q. Gong, L. Du, Y. Pan, and J. Liu, "Application and development of hard rock TBM and its prospect in China," Tunnelling and Underground Space Technology, vol. 57, pp. 33-46, 2016.

[4] J. Rostami, "Study of pressure distribution within the crushed zone in the contact area between rock and disc cutters," International Journal of Rock Mechanics and Mining Sciences, vol. 57, no. Suppl, pp. 172-186, 2013.

[5] H. Alehossein, E. Detournay, and H. Huang, "An analytical model for the indentation of rocks by blunt tools," Rock Mechanics and Rock Engineering, vol. 33, no. 4, pp. 267-284, 2000.

[6] B. R. Lawn and A. G. Evans, "A model for crack initiation in elastic/plastic indentation fields," Journal of Materials Science, vol. 12, no. 11, pp. 2195-2199, 1977.

[7] L. J. Yin, Q. M. Gong, H. S. Ma, J. Zhao, and X. B. Zhao, "Use of indentation tests to study the influence of confining stress on rock fragmentation by a TBM cutter," International Journal of Rock Mechanics and Mining Sciences, vol. 72, pp. 261-276, 2014.

[8] X. P. Zhou, S. F. Zhai, Q. M. Gong, and F. Berto, "Experimental study of the mechanism of TBM disk cutter penetration in mixed-faced grounds under confining pressure," Journal of Testing and Evaluation, vol. 48, no. 3, pp. 22702294, 2020.

[9] J.-W. Cho, S. Jeon, S.-H. Yu, and S.-H. Chang, "Optimum spacing of TBM disc cutters: a numerical simulation using the three-dimensional dynamic fracturing method," Tunnelling and Underground Space Technology, vol. 25, no. 3, pp. 230244, 2010.

[10] H. Huang and E. Detournay, "Discrete element modeling of tool-rock interaction II: rock indentation," International Journal for Numerical and Analytical Methods in Geomechanics, vol. 37, no. 13, pp. 1930-1947, 2013.

[11] H. Y. Liu, S. Q. Kou, P.-A. Lindqvist, and C. A. Tang, "Numerical simulation of the rock fragmentation process induced by indenters," International Journal of Rock Mechanics and Mining Sciences, vol. 39, no. 4, pp. 491-505, 2002.
[12] S. F. Zhai, X. P. Zhou, J. Bi, and Q. H. Qian, "Validation of GPD to model rock fragmentation by TBM cutters," International Journal of Geomechanics, vol. 17, no. 6, pp. 06016036-6016115, 2017.

[13] E. Farrokh, J. Rostami, and C. Laughton, "Study of various models for estimation of penetration rate of hard rock TBMs," Tunnelling and Underground Space Technology, vol. 30, pp. 110-123, 2012.

[14] J. Hassanpour, J. Rostami, and J. Zhao, "A new hard rock TBM performance prediction model for project planning," Tunnelling and Underground Space Technology, vol. 26, no. 5, pp. 595-603, 2011.

[15] Q. M. Gong, J. Zhao, and Y. S. Jiang, "In situ TBM penetration tests and rock mass boreability analysis in hard rock tunnels," Tunnelling and Underground Space Technology, vol. 22, no. 3, pp. 303-316, 2007.

[16] L. J. Yin, Q. M. Gong, and J. Zhao, "Study on rock mass boreability by TBM penetration test under different in situ stress conditions," Tunnelling and Underground Space Technology, vol. 43, pp. 413-425, 2014.

[17] C. Balci and D. Tumac, "Investigation into the effects of different rocks on rock cuttability by a V-type disc cutter," Tunnelling and Underground Space Technology, vol. 30, pp. 183-193, 2012.

[18] J.-W. Cho, S. Jeon, H.-Y. Jeong, and S.-H. Chang, "Evaluation of cutting efficiency during TBM disc cutter excavation within a Korean granitic rock using linear-cutting-machine testing and photogrammetric measurement," Tunnelling and Underground Space Technology, vol. 35, no. Suppl, pp. 37-54, 2013.

[19] Q. M. Gong, G. W. He, X. B. Zhao et al., "Influence of different cutter spacings on rock fragmentation efficiency of Beishan granite by TBM," Chinese Journal of Geotechnical Engineering, vol. 37, pp. 54-60, 2015, (in Chinese).

[20] H. Zhang, G. Huang, H. Song, and Y. Kang, "Experimental investigation of deformation and failure mechanisms in rock under indentation by digital image correlation," Engineering Fracture Mechanics, vol. 96, pp. 667-675, 2012.

[21] H. Song, H. Zhang, D. Fu et al., "Experimental study on damage evolution of rock under uniform and concentrated loading conditions using digital image correlation," Fatigue \& Fracture of Engineering Materials \& Structures, vol. 36, no. 8, pp. 760-768, 2013.

[22] Q. Liu, Q. Liu, Y. Pan, X. Peng, P. Deng, and K. Huang, "Experimental study on rock indentation using infrared thermography and acoustic emission techniques," Journal of Geophysics and Engineering, vol. 15, no. 5, pp. 1864-1877, 2018.

[23] J. Liu, P. Cao, and D. Han, "The influence of confining stress on optimum spacing of TBM cutters for cutting granite," International Journal of Rock Mechanics and Mining Sciences, vol. 88, pp. 165-174, 2016.

[24] J. Liu, P. Cao, and D. Han, "Sequential indentation tests to investigate the influence of confining stress on rock breakage by tunnel boring machine cutter in a biaxial state," Rock Mechanics and Rock Engineering, vol. 49, no. 4, pp. 1479-1495, 2016.

[25] Q. Liu, Y. Pan, J. Liu, X. Kong, and K. Shi, "Comparison and discussion on fragmentation behavior of soft rock in multiindentation tests by a single TBM disc cutter," Tunnelling and Underground Space Technology, vol. 57, no. Suppl, pp. 151161, 2016. 
[26] D. B. Marshall, "Geometrical effects in elastic/plastic indentation," Journal of the American Ceramic Society, vol. 67, pp. 57-60, 1984.

[27] S. H. Chang, S. W. Choi, Y. T. Park, G. P. Lee, and G. J. Bae, "Experimental evaluation of the effects of cutting ring shape on cutter acting forces in a hard rock," Journal of Korean Tunnelling \& Underground Space Association, vol. 15, pp. 225-235, 2013, in Korean.

[28] N. Bilgin, H. Copur, and C. Balci, "Effect of replacing disc cutters with chisel tools on performance of a TBM in difficult ground conditions," Tunnelling and Underground Space Technology, vol. 27, no. 1, pp. 41-51, 2012.

[29] Z. Guclucan, S. Meric, Y. Palakci et al., "The use of theoretical rock cutting concepts in explaining the cutting performance of a TBM using different cutter types in different rock formations and some recommendations," in Proceedings of World Tunnelling Congress, Safe Tunnelling for the City and for the Environment, pp. 487-489, Budapest, Hungary, 2009.

[30] S.-Q. Kou, Y. Huang, X.-C. Tan, and P.-A. Lindqvist, "Identification of the governing parameters related to rock indentation depth by using similarity analysis," Engineering Geology, vol. 49, no. 3-4, pp. 261-269, 1998.

[31] J. Rostami and L. Ozdemir, "A new model for performance prediction of hard rock TBMs," in Proceedings of Rapid Excavation and Tunneling Conference (RETC), pp. 793-809, Boston, MA, USA, 1993.

[32] L. L. Mishnaevsky Jr., "Physical mechanisms of hard rock fragmentation under mechanical loading: a review," International Journal of Rock Mechanics and Mining Sciences \& Geomechanics Abstracts, vol. 32, no. 8, pp. 763-766, 1995.

[33] Q. M. Gong, "Development of a brock mass characteristics model for TBM penetration rate prediction," $\mathrm{Ph}$. D thesis, Nan Technoliqical University, Singapore, Singapore, 2006.

[34] X. H. Yao, X. B. Zhao, Q. M. Gong et al., "Linear cutting experiments on crack modes of rock under indentation of a single disc cutter," Chinese Journal of Geotechnical Engineering, vol. 36, pp. 1705-1713, 2014, in Chinese.

[35] T. E. Brown, Rock Characterization, Testing \& Monitoring: ISRM Suggested Methods, Pergamon Press, Oxford, UK, 1981.

[36] D. Tumac and C. Balci, "Investigations into the cutting characteristics of CCS type disc cutters and the comparison between experimental, theoretical and empirical force estimations," Tunnelling and Underground Space Technology, vol. 45, pp. 84-98, 2015.

[37] ASTM (American Society for Testing and Materials), Standard Guide for Determining the Reproducibility of Acoustic Emission Sensor Response, Standard E976-15, ASTM, Philadelphia, PA, USA, 2015.

[38] B. Paul and D. L. Sikarskie, "A preliminary theory of static penetration by a rigid wedge into a brittle material," AIME Transactions, vol. 232, pp. 372-383, 1965.

[39] R. E. Gertsch, "Rock toughness and disc cutting," Ph. D thesis, University of Missouri, Rolla, MO, USA, 2000.

[40] M. H. Miller and D. L. Sikarskie, "On the penetration of rock by three-dimensional indentors," International Journal of Rock Mechanics and Mining Sciences \& Geomechanics Abstracts, vol. 5, no. 5, pp. 375-398, 1968.

[41] N. Bilgin, H. Copur, and C. Balci, TBM Excavation in Difficult Ground Conditions: Case Studies from Turkey, Wiley, Hoboken, NJ, USA, 2016.

[42] Z. Guclucan, S. Meric, M. Algan et al., "The use of a TBM in difficult ground conditions in beykoz-kavacik sewerage tunnel," in Proceedings of the World Tunnel Congress,
Underground Facilities for Better Environment and Safety, pp. 1630-1638, Agra, India, 2008.

[43] S. Chen, C. Yang, G. Wang, and W. Liu, "Similarity assessment of acoustic emission signals and its application in source localization," Ultrasonics, vol. 75, no. Suppl, pp. 36-45, 2017.

[44] M. Ge, "Analysis of source location algorithms: Part II. Iterative methods," Journal of Acoustic Emission, vol. 21, pp. 29-51, 2003.

[45] J.-P. Liu, Y.-H. Li, S.-D. Xu, S. Xu, C.-Y. Jin, and Z.-S. Liu, "Moment tensor analysis of acoustic emission for cracking mechanisms in rock with a pre-cut circular hole under uniaxial compression," Engineering Fracture Mechanics, vol. 135, pp. 206-218, 2015.

[46] Q. Liu, Q. Liu, Y. Pan, X. Liu, X. Kong, and P. Deng, "Microcracking mechanism analysis of rock failure in diametral compression tests," Journal of Materials in Civil Engineering, vol. 30, no. 6, pp. 04018082-4018114, 2018.

[47] Y. A. Tan, "Analysis of fractured face of rock burst with scanning electron microscope and its progressive failure process," Journal of Chinese Electron Microscopy Society, vol. 2, pp. 41-48, 1989, in Chinese.

[48] X. M. Liu and C. F. Lee, "Microfailure mechanism analysis and test study for rock failure surface," Chinese Journal of Geotechnical Engineering, vol. 16, pp. 509-513, 1997, in Chinese. 